\title{
THE
}

\section{Determinants of spread in an urban landscape by an introduced lizard}

Jason J. Kolbe

University of Rhode Island, jjkolbe@uri.edu

Paul VanMiddlesworth

Andrew C. Battles

University of Rhode Island

James T. Stroud

Bill Buffum

University of Rhode Island, bill_buffum@uri.edu

Follow this and additional works at: https://digitalcommons.uri.edu/bio_facpubs

The University of Rhode Island Faculty have made this article openly available.

Please let us know how Open Access to this research benefits you.

This is a pre-publication author manuscript of the final, published article.

Terms of Use

This article is made available under the terms and conditions applicable towards Open Access

Policy Articles, as set forth in our Terms of Use.

\section{Citation/Publisher Attribution}

Kolbe, J.J., VanMiddlesworth, P., Battles, A.C. et al. Landscape Ecol (2016) 31: 1795. https://doi.org/ 10.1007/s10980-016-0362-1

Available at: https://doi.org/10.1007/s10980-016-0362-1 


\section{Authors}

Jason J. Kolbe, Paul VanMiddlesworth, Andrew C. Battles, James T. Stroud, Bill Buffum, Richard T. T.

Forman, and Jonathan B. Losos

This article is available at DigitalCommons@URI: https://digitalcommons.uri.edu/bio_facpubs/178 
1 Determinants of spread in an urban landscape by an introduced lizard

2

3 Jason J. Kolbe • Paul VanMiddlesworth • Andrew C. Battles • James T. Stroud •

4 Bill Buffum • Richard T.T. Forman • Jonathan B. Losos

$6 \quad$ J. J. Kolbe (Corresponding author) • A. C. Battles

7 Department of Biological Sciences, University of Rhode Island, 120 Flagg Rd.,

8 Kingston, RI, 02881, USA

9 e-mail: jjkolbe@uri.edu

10 phone: $401-874-9731$

11

12 P. VanMiddlesworth $\bullet$ J. B. Losos

13 Department of Organismic and Evolutionary Biology and Museum of Comparative

14 Zoology, Harvard University, 26 Oxford St., Cambridge, MA 02138, USA

15

J. T. Stroud

17 Department of Biological Sciences, Florida International University, Miami, FL,

18 33199, USA

19

B. Buffum

Department of Natural Resources Science, 1 Greenhouse Rd., University of Rhode

22 Island, Kingston, RI, 02881, USA

23

R. T. T. Forman

25 Graduate School of Design, Harvard University, 48 Quincy St., Cambridge, MA,

26 02138, USA

27

Date of the manuscript draft: November 2, 2015 


\section{Abstract}

36 Context

37 Urban landscapes are a mixture of built structures, human-altered vegetation, and

38 remnant semi-natural areas. The spatial arrangement of abiotic and biotic

39 conditions resulting from urbanization doubtless influences the establishment and

40 spread of non-native species in a city.

41

42 Objectives

43 We investigated the effects of habitat structure, thermal microclimates, and species

44 coexistence on the spread of a non-native lizard (Anolis cristatellus) in the Miami

45 metropolitan area of South Florida (USA).

46

47 Methods

48 We used transect surveys to estimate lizard occurrence and abundance on trees and

49 to measure vegetation characteristics, and we assessed forest cover and impervious

50 surface using GIS. We sampled lizard body temperatures, habitat use, and relative

51 abundance at multiple sites.

53 Results

54 At least one of five Anolis species occupied 79\% of the 1,035 trees surveyed in

55 primarily residential areas, and non-native $A$. cristatellus occupied $25 \%$ of trees.

56 Presence and abundance of $A$. cristatellus were strongly associated with forest

57 patches, dense vegetation, and high canopy cover, which produced cooler 
58 microclimates suitable for this species. Presence of A. cristatellus was negatively

59 associated with the ecologically similar non-native A. sagrei, resulting in reduced

60 abundance and a shift in perch use of $A$. cristatellus.

61

62 Conclusions

63 The limited spread of A. cristatellus in Miami over 35 years is due to the patchy, low-

64 density distribution of wooded habitat, which limits dispersal by diffusion. The

65 presence of congeners may also limit spread. Open habitats - some parks, yards

66 and roadsides - contain few if any A. cristatellus, and colonization of isolated forest

67 habitat appears to depend on human-mediated dispersal.

68

69 Keywords

70 Anolis - body temperature - canopy cover - GIS - forest cover - impervious surface -

71 thermal microclimates - tree characteristics - urban heat island - urban vegetation

72

73 


\section{Introduction}

75 Upon arrival in a city, non-native species encounter a spatially

76 heterogeneous environment that varies in the types and densities of buildings,

77 vegetation, infrastructure, and remnant natural areas (Pickett et al. 2001; Cadenasso

78 et al. 2007; Forman 2014). This variability in habitat structure and its spatial

79 patterning will likely influence the ability of invaders to establish and spread within

80 an urban area. For example, exotic grey squirrels in the UK are positively associated

81 with increased canopy cover, larger trees, and the presence of seed-bearing trees as

82 well as supplementary feeders for birds (Bonnington et al. 2014). Thus, the

83 arrangement of vegetation and non-vegetative features within the urban landscape

84 influences where exotics establish and the routes by which they spread. Identifying

85 those features associated with the occurrence of exotic species is important for

86 understanding their current distributions and potential for future spread.

87 As a consequence of habitat structure modification during urbanization, city

88 temperatures can be several degrees higher than surrounding rural areas (Akbari et

89 al. 2001; Arnfield 2003; Chen and Jim 2008; Rizwan et al. 2008). These urban heat

90 islands are spatially and temporally heterogeneous (Ramalho and Hobbs 2011),

91 reflecting variation in the matrix of built structures and local vegetation and

92 creating a thermal mosaic (Georgi and Zafiriadis 2006; Hamdi and Schayes 2008;

93 Huang et al. 2008). This variation influences the microclimates available in a city,

94 including air and surface temperatures, relative humidity, solar radiation, and wind

95 speed. Thermal microclimates are critically important to ectotherms (e.g., insects,

96 lizards, frogs), which rely on external sources of heat to regulate their body 
97 temperatures. Because temperature is fundamentally important for development,

98 growth, survival, and reproduction in ectotherms (Angilletta 2009), organisms

99 living in a city are likely to be sensitive to variation in vegetation and urban features

100 that affect thermal microclimates (Ackley et al. 2015a).

101 In addition to the habitat structure of a city, interactions with potential

102 competitors and predators can influence occurrence and abundance patterns

103 (Shochat et al. 2006; Anderson and Burgin 2008). For example, abundance of a

104 native gecko, Lepidodactylus lugubris, throughout the Pacific is strongly influenced

105 by interactions with a competitively superior non-native gecko, Hemidactylus

106 frenatus (Case et al. 1994), which better exploits insect resources concentrated

107 under artificial night lighting (Petren and Case 1996). In general, more ecologically

108 similar species are predicted to have stronger negative effects on each other at local

109 scales through competition (Pianka 1981; Losos 1994). Thus, both biotic and

110 abiotic factors may influence the establishment, spread, and ultimately the

111 distribution of non-native species in a city.

112 In this study, we investigate the effects of habitat structure, thermal

113 microclimates, and species interactions on the spread of introduced Anolis lizards in

114 the Miami metropolitan area. Our study group, Anolis lizards (or anoles), comprise a

115 species-rich genus of small, insectivorous, diurnal lizards found in the Neotropics

116 from the southeastern United States to South America including Caribbean islands

117 (Losos 2009). Many Anolis species occupy both natural and human-modified areas

118 in their native and non-native ranges (Perry et al. 2008; Irschick et al. 2005;

119 Marnocha et al. 2011; Kolbe et al. 2015). There are nine Anolis species established 
120 in Miami, only one of which - A. carolinensis - is native to the U.S. (Lever 2003;

121 Kolbe et al. 2007; Kraus 2009). Four species have very restricted distributions ( $A$.

122 chlorocyanus, A. cybotes, A. garmani and A. porcatus), two are distributed throughout

123 the Miami area (A. distichus and A. equestris), and one is found throughout Florida,

124 the Gulf Coast, and southern Georgia and South Carolina (A. sagrei). In contrast to

125 these either very restricted or widespread species, an eighth non-native species, $A$.

126 cristatellus (Fig. 1, inset), is expanding its distribution in Miami, but is not yet

127 ubiquitous. We can therefore identify factors related to its current distribution and

128 predict whether future spread in urban areas is likely.

129 Anolis lizards have a number of advantages for this study. First, anoles in

130 Miami are conspicuous, easy to detect, and sufficiently different in ecology and

131 morphology to accurately identify to species when present. Second, the

132 introduction history of A. cristatellus in Miami is well studied with two independent

133 introductions from its native range in Puerto Rico (Kolbe et al. 2007). Third, the

134 other four Anolis species that co-occur with A. cristatellus in Miami - A. carolinensis,

135 A. distichus, A. equestris and A. sagrei - were all present prior to its introduction in

136 the mid-1970s. These species span a range of ecological similarity; specifically, $A$.

137 sagrei and A. distichus typically perch lower to the ground on tree trunks, similar to

138 A. cristatellus, whereas $A$. carolinensis and A. equestris perch higher in the canopy

139 (Losos 2009). We can therefore test the hypothesis that more ecologically similar

140 congeners influence the presence of $A$. cristatellus in Miami. Lastly, the thermal

141 biology of anoles in general, and A. cristatellus in particular, is well studied (Losos

142 2009). Previous studies detail the thermal preferences, thermal tolerances, and 
143 field body temperatures of A. cristatellus from numerous sites in Puerto Rico and

144 Miami (e.g., Huey 1974; Huey and Webster 1976; Hertz 1992; Leal and Gunderson

145 2012; Kolbe et al. 2012; Gunderson and Leal 2012), allowing us to evaluate if the

146 effects of urban vegetation on thermal microclimates are relevant to A. cristatellus.

147 A primary goal of this study is to contrast how abiotic and biotic aspects of

148 the urban environment influence the current distribution and abundance of a

149 recently introduced species to better understand its potential for future spread. We

150 survey lizards and vegetation characteristics on a tree-by-tree basis using transects

151 across putative distribution boundaries, and test for relationships at the landscape

152 level between the presence of $A$. cristatellus and GIS-based data attributes of forest

153 cover and impervious surfaces. We predict that 1) urban vegetation structure and

154 arrangement will influence the occurrence and abundance of $A$. cristatellus. In

155 particular, we predict that $A$. cristatellus will be associated with denser vegetation

156 and forested areas, which produce relatively cooler microclimates. Based on

157 previous ecological studies (Losos 2009), we also predict 2) negative associations

158 between A. cristatellus and its more ecologically similar congeners in Miami.

159 Specifically, A. sagrei and A. distichus overlap most with A. cristatellus in their

160 structural microhabitat (i.e., the height, diameter, and type of perch), which should

161 lead to stronger interspecific competition.

162

\section{Methods}

164 Studyarea 
166 sites of introductions for A. cristatellus are documented. Genetic analyses confirmed

167 two independent introductions from geographically and genetically distinct native-

168 range sources in Puerto Rico (Kolbe et al. 2007). The Key Biscayne population is

169 from San Juan, Puerto Rico and was first detected in a residential area on the island

170 in 1975 (Schwartz and Thomas 1975; Bartlett and Bartlett 1999). The South Miami

171 population is from northeast Puerto Rico and was found in a different residential

172 area in 1976 (Wilson and Porras 1983). The Key Biscayne population is $\sim 5 \mathrm{~km}$ from

173 the mainland population separated by a bridge to Virginia Key and the Rickenbacker

174 Causeway to the mainland. The two introduction sites are $\sim 12 \mathrm{~km}$ apart across

175 Biscayne Bay. The bulk of the study area is residential with detached single units,

176 considerable tree cover, and low-traffic, two-lane roads. Also present are

177 commercial districts, high-traffic roads up to six lanes, open parklands, urban

178 forests, and waterways such as canals, lakes, and coastal areas (Fig. 1,

179 Supplementary Fig. 1).

\section{$181 \quad$ Study design and sampling}

182 In summer 2009, we collected preliminary data on A. cristatellus presence in

183 the Miami area by conducting block-by-block walking surveys radiating from the

184 initial points of introduction in South Miami and Key Biscayne. Based on these data,

185 we established five $610 \mathrm{~m}$ x $1100 \mathrm{~m}$ plots in South Miami, each crossing an observed

186 transition from presence to absence of A. cristatellus. In each plot, we established

187 three to six roadside transects running perpendicular to the transition zone 
188 (Supplementary Fig. 2). On our initial visit to each transect in June 2010, we

189 measured tree characteristics (Table 1) and, using binoculars when needed,

190 observed Anolis lizards on trees with a trunk diameter $>10 \mathrm{~cm}$ growing in the

191 roadside public right-of-way. Although lizards use smaller trees, the availability of

192 such trees was limited along roadsides and in yards. All species have multiple

193 diagnostic features, which aided accurate species identification. Following this

194 initial survey, we returned to each transect two more times to survey the same trees

195 for the presence and total number of lizards of the five Anolis species. One to three

196 trained observers were present for each survey, with at least two observers in most

197 cases. Data from these transects were used to evaluate whether the presence of $A$.

198 cristatellus was related to the presence of congeners and to the characteristics of the

199 trees and surrounding vegetation (Table 1).

200 Given patterns of species coexistence from these transects, we conducted

201 visual encounter surveys to determine if congener presence affects the relative

202 abundance and habitat use of A. cristatellus (Crump and Scott 1994; Kolbe et al.

203 2008). Surveys consisted of walking at a constant pace for 15 minutes and

204 recording the species, time, sex, and perch characteristics (i.e., height and diameter)

205 for all undisturbed lizards observed. We compared relative abundance at sites with

206 predominantly A. cristatellus ( $\mathrm{n}=10$ surveys) to sites with $A$. distichus and A. sagrei in

207 addition to $A$. cristatellus ( $\mathrm{n}=6$ surveys). Because A. distichus and A. sagrei co-occur

208 throughout most of Miami, we were unable to find nearby sites with only one of

209 these species. We supplemented data on perch characteristics with opportunistic

210 observations of all three species at the same sites. 
212 opportunistic surveys allowed us to map the distribution of $A$. cristatellus in Miami

213 (Figs. 1 and 2). In addition to the intensive sampling within the core areas of South

214 Miami and Key Biscayne, we also investigated potential localities throughout Miami-

215 Dade County including municipal parks and regional waste transfer stations.

216 Preliminary surveys showed A. cristatellus was present in forest patches in some

217 parks associated with waste transfer stations, suggesting transport of yard waste

218 from houses to regional stations as a potential dispersal mechanism.

219

220 GIS analysis of forest cover and impervious surfaces

221 To complement analyses based on transect data, we conducted a geographic

222 information system (GIS) analysis of the study area using ArcGIS version 10.2

223 (Environmental Systems Research Institute, Redlands, CA) and publicly available

224 GIS layers of impervious surface (MRLC 2011) and forest fragmentation (NOAA

225 2010). The MRLC Percent Developed Imperviousness layer, a raster dataset with

226 30-meter pixels, provides the average percentage of human-made impervious

227 surface for each pixel. The NOAA forest fragmentation layer, a raster dataset with

228 30-meter pixels, distinguishes between four fragmentation types: 1) "core forest"

229 refers to forested pixels that are not adjacent to any non-forested pixels, 2) "patch

230 forest" refers to forested pixels in small patches that are not large enough to contain

231 a 90m x 90m block of forest, 3) "perforated forest" refers to forested pixels adjacent

232 to small non-forested patches that are not large enough to contain a $90 \mathrm{~m} \times 90 \mathrm{~m}$

233 block of non-forested area, and 4) "edge forest" refers to forested pixels adjacent to

234 larger non-forested patches that contain at least one $90 \mathrm{~m}$ x 90m block of non- 
235 forested area. We used GIS to generate 11 attributes describing forests and

236 impervious surfaces (Table 2).

238 Thermal microclimates and lizard body temperatures

239 To investigate the range of possible thermal microclimates available to $A$.

240 cristatellus in Miami during peak summer temperatures, we measured the

241 temperature under two trees-one with an open canopy (Thrinax radiata, DBH $=12$

$242 \mathrm{~cm}$ ) and another with a heavily shaded canopy (Chukrasia tabularis, DBH $=145 \mathrm{~cm}$ ).

243 We used painted, hollow, copper models the size of lizards with an iButton inside to

244 estimate temperatures a lizard would experience in each location without

245 behavioral or physiological thermoregulation (Hertz 1992; Gunderson and Leal

246 2012; Ackley et al. 2015a). Temperatures were recorded every 15 minutes on the

247 north, south, east, and west sides of each tree at a height of $1.5 \mathrm{~m}$ from $1700 \mathrm{~h}$ on

248 July 17 to $1000 \mathrm{~h}$ on July 21,2014 . To estimate the percentage of open canopy, we

249 took hemispherical canopy photographs in each cardinal direction using a $180^{\circ}$

250 fisheye lens and analyzed them using Gap Light Analyzer version 2.0 (Frazer et al. 251 1999).

252 To estimate the range of field body temperatures $\left(\mathrm{T}_{\mathrm{b}}\right)$ for A. cristatellus in

253 Miami, we sampled lizards and random locations at three sites that varied in species

254 composition and vegetative structure. For comparative purposes, we also sampled

255 A. sagrei, which has both higher field $\mathrm{T}_{\mathrm{b}}$ and thermal tolerances than A. cristatellus

256 (Corn 1971; Lee 1980; Gunderson and Leal 2012; Kolbe et al. 2012, 2014). The sites

257 included a bike path along a canal where both species were sampled, a residential 
258 area where only A. sagrei was sampled, and a forested area where only A. cristatellus

259 was sampled. For each undisturbed lizard captured, we recorded $\mathrm{T}_{\mathrm{b}}$, air

260 temperature $1 \mathrm{~cm}$ above the substrate where the lizard was perched, and copper

261 lizard model temperature at the same location as the lizard using a thermocouple

262 probe connected to a digital thermometer (Omega HH802U). We then took a

263 hemispherical canopy photo to estimate canopy openness as described above. For

264 comparison, we took copper lizard model temperature, air temperature, and a

265 canopy photo at randomly selected locations within each study site. Lizard $\mathrm{T}_{\mathrm{b}}$ and

266 random location data were collected between 0800 to $1400 \mathrm{~h}$, which is a high-

267 activity time of day during the summer.

268

269 Data analysis

270 Occupancy and estimates of detection probabilities were calculated using single 271 season occupancy models (MacKenzie et al. 2002) in the program PRESENCE (Hines

272 2006). Likelihood models calculated in PRESENCE all assume that 1) any site where a

273 species is present remains occupied, 2) species may or may not be detected when present,

274 but are not detected when absent, and 3) the detection of a species at one sampling site is

275 independent of detection at all other sites (MacKenzie et al. 2002). A minimum of two

276 sample occasions is required for model estimation. We conducted three repeat surveys at

277 each sampling point. Occupancy models to calculate estimates of detection were

278 produced with all surveyors (Rick Stanley [RS], PV, and JJK) independently as

279 covariates as well as using full identity models including all surveyors. 
We used generalized linear models (GLM; McCullagh and Nelder 1989; R

281 2013) with binomial (presence-absence) and continuous (abundance) response

282 variables. This allowed us to form linear and quadratic relationships between the

283 response and explanatory variables (Broennimann et. al. 2012), which were

284 standardized to normalize their distributions. Explanatory variables included the

285 tree characteristics of trunk diameter, canopy diameter, distance to nearest plant,

286 distance to nearest tree, and overstory canopy cover (Table 1). Model selection was

287 performed using a stepwise procedure based on the Akaike information criterion

288 (AIC; Akaike 1974). We conducted three separate analyses using presence-absence

289 as the response variable. First, we compared transect sections with A. cristatellus

290 present (but not necessarily occupying every tree) versus sections where $A$.

291 cristatellus was absent; second, we compared the presence versus absence of $A$.

292 cristatellus on all trees pooled; and third, we compared the presence versus absence

293 of A. cristatellus on trees within only the sections of transects with A. cristatellus

294 present. We then repeated the latter two analyses using A. cristatellus abundance as

295 the response variable.

296 When analyzing the GIS-based attributes, we conducted two separate

297 analyses. First, we divided street blocks from each transect into those with $A$.

298 cristatellus present versus absent and compared attributes derived from GIS (Table

299 2). Second, we used presence and absence points for individual observations

300 throughout the Miami metropolitan area to test for relationships with GIS-derived

301 attributes, restricting the data set to no more than one observation per block. 
303 to compare tree characteristics between sections of transects with A. cristatellus

304 present versus absent. When evaluating A. cristatellus abundance in relation to

305 categorical tree characteristics, we used t-tests or analyses of variance (ANOVA) as

306 appropriate. We tested for a relationship between the presence-absence of $A$.

307 cristatellus and the presence-absence of the four congeners using likelihood ratio

308 tests. We tested for effects using all trees sampled, as well as only those trees on the

309 sections of transects with A. cristatellus present. Analyses were conducted for trees

310 on each plot separately and with trees from all plots pooled.

311 Relative abundances from the visual encounter surveys were not normally

312 distributed, so we used a Wilcoxon test to evaluate whether differences existed

313 between sites. In particular, we predicted relative abundance of $A$. cristatellus

314 would decrease when it is with other Anolis species compared to being alone. Log-

315 transformation achieved normality for perch height and diameter, and we tested for

316 a difference in these perch characteristics for A. cristatellus between sites with and

317 without congeners using t-tests.

318 We compared lizard $\mathrm{T}_{\mathrm{b}}$ and copper lizard model temperatures at the same

319 locations using linear regression. Using this calibration, we adjusted model

320 temperatures to make them directly comparable to lizard $\mathrm{T}_{\mathrm{b}}$ for both species. We

321 averaged model temperatures by hour and plotted them against time of day. We

322 compared these model temperature estimates (i.e., non-thermoregulating lizards) to

323 field $\mathrm{T}_{\mathrm{b}}$ collected at the same time of year, and literature estimates of preferred $\mathrm{T}_{\mathrm{b}}$

324 and high temperature tolerance (i.e., critical thermal maximum, or CTmax) for $A$. 
325 cristatellus (Huey and Webster 1976). To investigate variation in field $\mathrm{T}_{\mathrm{b}}$ of lizards,

326 we conducted an analysis of covariance (ANCOVA) testing for differences among

327 groups (i.e., A. cristatellus, A. sagrei, and random locations) with air temperature,

328 time of day, and canopy openness as covariates. We used the Johnson-Neyman

329 procedure (White 2003) to determine the range of covariate values in which

330 temperatures differed between groups when regression slopes were heterogeneous

331 (i.e., a significant interaction between the main effect and covariate).

332

333

334

335

336

337

338

339

340 Miami metropolitan area $(n=362$ presence points and $n=483$ absence points; Fig. 1,

341 Supplementary Fig. 1). This species has expanded its core range from the original

342 point of introduction no more than $2 \mathrm{~km}$ to the west, south, and east in South Miami,

343 and $\sim 7 \mathrm{~km}$ to the northeast. A six-lane highway (i.e., the Dixie Highway/US 1) to the

344 northwest of the core South Miami distribution appears to limit unaided dispersal.

345 The introduction to Key Biscayne expanded across the majority of the island, but not

346 across the bridge to Virginia Key or causeway to mainland Miami.

347 We detected seven disjunct populations ranging from $<1$ to $20 \mathrm{~km}$ from the

348 core distribution in South Miami. These sites included several Miami-Dade County

349 Parks (i.e., Chapman Fields, Kendall Indian Hammock, and Oak Grove) as well as the

350 University of Miami campus and three residential areas. We found A. cristatellus at 
351 two of 13 waste transfer stations in Miami-Dade County (i.e., Chapman Fields and

352 Sunset Kendall), but only when adjacent to forested parks. Most waste transfer

353 stations had only a few widely spaced trees and were surrounded by residential or

354 commercial areas. Other species were present at all waste transfer stations with $A$.

355 distichus and $A$. sagrei being the most common.

356

357

358

359

360

361 (Table 3). The best models to estimate detection probabilities for each species were

362 single season occupancy models including all three surveyors. Estimates of among-

363 surveyor detection probability for the focal species, A. cristatellus, ranged from 0.50-0.96

364 among sites, and average detection probability for each surveyor for all sites was

365 estimated at $0.63-0.90$ (Supplementary Table 1). Total detection probability for the full

366 model (all surveyors) was estimated at $0.88( \pm 0.12)$. These estimates for detection were

367 high and therefore detection probabilities were not considered influential in subsequent

368 analyses. The most likely models of tree characteristics found $A$. cristatellus

369 associated with trees having larger trunks, larger canopies, greater percent of

370 overstory canopy cover, and closer to other plants and trees (Tables 1 and 4). These

371 results suggest that $A$. cristatellus occupies relatively shady and densely vegetated

372 areas.

373 Sections of transects with A. cristatellus present had a greater proportion of

374 native trees $\left(X^{2}=12.3, \mathrm{df}=1, \mathrm{P}<0.001, \mathrm{n}=937\right)$ and trees with smooth bark $\left(X^{2}=14.4\right.$,

$375 \mathrm{df}=4, \mathrm{P}<0.01, \mathrm{n}=1035$ ) as compared to transect sections with A. cristatellus absent. 
376 In contrast, transect sections with and without $A$. cristatellus did not differ in the

377 proportion of palm trees $\left(X^{2}=0.5, \mathrm{df}=1, \mathrm{P}=0.46, \mathrm{n}=1028\right)$ or the number of trunks on

378 trees $\left(X^{2}=4.3, \mathrm{df}=2, \mathrm{P}=0.12, \mathrm{n}=1035\right)$.

379 Models for the abundance of A. cristatellus showed similar results with

380 increased abundance associated with trees having larger trunks and canopies,

381 greater percent of canopy cover, and closer to other plants (Table 4). Anolis

382 cristatellus abundance was twice as high on non-palm compared to palm trees

$383(t=2.7, d f=1026, P<0.01)$ and highest on trees with multiple trunks $\left(F_{2,1032}=14.9\right.$,

$384 \mathrm{P}<0.0001)$, which were often large Ficus trees. Abundance did not differ between

385 native and non-native trees $(\mathrm{t}=-1.08, \mathrm{df}=935, \mathrm{P}=0.28)$ or among bark textures

$386 \quad\left(\mathrm{~F}_{4,1030}=1.57, \mathrm{P}=0.18\right)$.

$387 \quad$ Analyses of A. cristatellus presence using GIS-based attributes were

388 consistent with transect surveys. Blocks with A. cristatellus present had more trees

389 per km, greater canopy cover, denser vegetation, and less impervious surface area

390 (Table 5A). Similarly, when analyzing the presence-absence points across Miami, $A$.

391 cristatellus was present at locations with less impervious surface and closer to

392 larger blocks of forest but not smaller forest patches (Fig. 2; Supplementary Fig. 3;

393 Table 5A). The percentage of forested area was three times greater in the core area

394 of A. cristatellus' distribution compared to the study area as a whole (Supplementary

395 Table 2). Moreover, the percentage of the core area with high impervious surface (>

$39640 \%$ ) was about half as much as the study area as a whole (Supplementary Table 2).

397

398 Congener presence 
Pooling all trees sampled, $A$. distichus and $A$. sagrei were both significantly

400 more likely to be absent when A. cristatellus was present than expected by chance,

401 with effects involving $A$. sagrei being much stronger (Table 6A). The presence of $A$.

402 carolinensis or $A$. equestris had no effect. When evaluating each plot separately, a

403 negative effect was observed with $A$. sagrei for most plots, and with $A$. carolinensis

404 and $A$. distichus in a few plots (Table 6A). This suggests congeneric interactions may

405 differ among plots. All comparisons for individual transects were non-significant

406 (results not shown).

407 Dividing each transect into sections based on A. cristatellus presence or

408 absence, only A. sagrei was more likely to be absent where A. cristatellus was

409 present (Table 6B). There was no interaction with the less abundant species $A$.

410 carolinensis and $A$. equestris. In contrast to the analyses of all trees pooled, this

411 analysis revealed no relationship between occurrence of $A$. distichus and $A$.

412 cristatellus (Table 6B). Potential interactions for A. cristatellus appear to be

413 strongest with $A$. sagrei, followed by $A$. distichus, but little evidence existed for

414 interactions with A. carolinensis or A. equestris.

415

416 Relative abundance and habitat use

417 Relative abundance estimates from visual encounter surveys were consistent 418 with the negative relationship between the presence of $A$. cristatellus and two of its 419 congeners in Miami. Anolis cristatellus was four times more abundant at sites with 420 no congeners than in sites occupied by $A$. distichus and $A$. sagrei (mean \pm SE: $45.3 \pm 2.5$

421 versus $11.0 \pm 3.2$ per survey; Wilcoxon: $\mathrm{Z}=3.21, \mathrm{P}<0.01)$. Furthermore, at sites with 
422 congeners, $A$. cristatellus perched nearly twice as high (mean \pm SE: $79.0 \pm 4.2 \mathrm{v}$.

$42347.2 \pm 1.8 ; \mathrm{t}=6.38, \mathrm{df}=608, \mathrm{P}<0.0001$ ) and on trunk substrates twice as wide

424 (mean \pm SE: $18.6 \pm 1.5$ v. $9.5 \pm 0.67 ; t=6.1 \mathrm{df}=604, \mathrm{P}<0.0001$ ), suggesting a possible shift

425 in habitat use in the presence of congeners.

426

427 Thermal microclimates and lizard body temperatures

428 We investigated the thermal consequences of canopy cover by comparing

429 copper lizard model temperatures under trees with open versus shaded canopies.

430 The percentage of overstory canopy cover ranged from 31-46\% for the open canopy

431 tree versus $89-91 \%$ for the shaded canopy tree (Supplementary Fig. 4). Model

432 temperatures for the two trees were similar through the night from $\sim 1900 \mathrm{~h}$ to

$433 \sim 0800 \mathrm{~h}$ (Fig. 3). After $0800 \mathrm{~h}$, model temperatures on the open canopy tree

434 increased quickly, exceeding both shaded tree temperatures and preferred

435 temperatures of $A$. cristatellus from $1000-1800 \mathrm{~h}$. While there was little variation in

436 model temperatures among the sides of the shaded tree, temperatures on the sides

437 of the open tree differed substantially from one another, with a maximum difference 438 of $5.7^{\circ} \mathrm{C}$ at $1000 \mathrm{~h}$.

439 Lizard $\mathrm{T}_{\mathrm{b}}$ and model temperatures showed a strong positive correlation

$440 \quad(\mathrm{r}=0.91 ; \mathrm{P}<0.0001, \mathrm{n}=52)$, suggesting that models accurately reflected lizard body

441 temperatures. ANCOVA results showed all three covariates had significant positive

442 effects on $\mathrm{T}_{\mathrm{b}} /$ model temperatures (canopy openness: $\mathrm{F}_{1,83}=46.42$, $\mathrm{P}<0.0001$; air

443 temperature: $\mathrm{F}_{1,83}=7.97, \mathrm{P}=0.006$; time of day: $\mathrm{F}_{1,83}=23.51, \mathrm{P}<0.0001$; whole model

$444 \mathrm{R}^{2}=0.67$ ). Anolis sagrei field body temperatures (mean $\pm \mathrm{SE}: 31.2^{\circ} \mathrm{C} \pm 0.4$ ) were 
445 significantly higher than $A$. cristatellus temperatures (mean $\pm \mathrm{SE}: 28.8^{\circ} \mathrm{C} \pm 0.4$;

$446 \quad F_{2,83}=3.79, P=0.03$; Tukey's HSD post hoc test $\mathrm{P}<0.05$; Fig. 4). However, because the

447 species by canopy openness interaction was significant this main effect should not

448 be interpreted directly but only in conjunction with the covariate. The relationship

449 between temperature and canopy openness had a much steeper slope for $A$.

450 cristatellus compared to $A$. sagrei and random points $(\mathrm{P}<0.05$ for comparison of

451 slopes; Fig. 4). The Johnson-Neyman procedure supported Tb differences between

452 A. cristatellus and both A. sagrei and random points for relatively closed canopies

453 (i.e., $<15 \%$ openness). In summary, all covariates had significant effects on lizard

$454 \mathrm{~T}_{\mathrm{b}}$, but A. cristatellus had lower $\mathrm{T}_{\mathrm{b}}$ compared to A. sagrei and the two species

455 appeared to thermoregulate differently in closed canopy areas.

456

457

458

459

460

461

462

463

464

465

466

467

468

469

\section{Discussion}

Since its introduction to South Miami over 40 years ago, A. cristatellus has spread only modestly by diffusion $(\sim 0.2-0.25 \mathrm{~km} / \mathrm{yr})$, much slower than some of the other introduced Anolis species in Miami and invasive species in general (Lockwood et al. 2007; Davis 2009). A recent analysis shows an order of magnitude faster spread rates on average for exotic lizards and snakes $(\sim 3 \mathrm{~km} / \mathrm{yr})$ and invaders to the Nearctic ( $\sim 5 \mathrm{~km} / \mathrm{yr}$; Liu et al. 2014). Results from our study suggest that both abiotic and biotic factors contribute to the limited spread of $A$. cristatellus in urban Miami. The fragmentation of suitable habitat is an abiotic constraint. The presence of $A$. cristatellus is strongly associated with forest habitats, which result in cooler and more humid microclimates (e.g., Wong and Yu 2005; Georgi and Zafiriadis 2006; 
470 Millward et al. 2014; Ackley et al. 2015a; Fig. 3). Because forests are patchily

471 distributed in Miami (Fig. 2a), dispersal by diffusion will be limited by

472 fragmentation caused by canals, non-forest habitats, and areas of impervious

473 surface, such as buildings, roads, and parking lots (Fig. 2). Therefore, human-

474 mediated dispersal may be an important mechanism for moving A. cristatellus to

475 isolated patches of suitable habitat, which lizards are unable to reach via natural

476 diffusion.

477 Interactions with ecologically similar congeners may be a biotic constraint.

478 Anolis cristatellus is spreading into areas occupied by one or more additional Anolis

479 species. As expected, we found negative associations between A. cristatellus and

480 ecologically similar A. sagrei and A. distichus, but weak or no relationship between

481 the occurrence of A. cristatellus and A. carolinensis or A. equestris, which typically

482 perch higher in the canopy (Losos 2009). Ultimately, the relative abundance of each

483 species and the extent to which they overlap on niche axes, such as structural

484 habitat and thermal microclimate, will determine whether and how quickly $A$.

485 cristatellus spreads to new areas.

486

487 Effect of urban vegetation on the spread of A. cristatellus

488 The presence and abundance of introduced A. cristatellus in Miami are

489 positively associated with larger trees, denser vegetation, greater canopy cover,

490 proximity to forest, and less impervious surface. These features are indicative of

491 forest patches in the urban environment including parks and certain residential

492 areas. Previous studies show patterns of urban vegetation can be related to 
493 numerous factors including socio-economics, remnant natural habitats, and

494 neighborhood age and history (e.g., Nowak et al. 1996; Martin et al. 2004; Grove et

495 al. 2006; Jenerette et al. 2007; Luck et al. 2009; Boone et al. 2010; Forman 2014).

496 Anolis cristatellus was present in several tropical hardwood hammocks, including

497 parks outside of its core distribution in South Miami. These disjunct populations

498 suggest dispersal limitation, not lack of suitable habitat, slows the spread of $A$.

499 cristatellus outside its core area in South Miami. The patchwork of scarce suitable

500 forested habitat in Miami will continue to limit the spread of A. cristatellus by

501 diffusion, making human transport an important dispersal mechanism. The

502 presence of A. cristatellus at forested parks located adjacent to spatially isolated

503 regional waste transfer stations suggests yard waste collection and transport may

504 be one such method of dispersal.

505 Vegetation in some residential areas within the core distribution of $A$.

506 cristatellus can change rapidly over short distances, likely affecting the ability of $A$.

507 cristatellus to spread to new areas. The transition from presence to absence of $A$.

508 cristatellus coincides with an abrupt increase in impervious surface and a loss of

509 forest habitat in some areas (see Fig. 2). The current distribution of A. cristatellus

510 includes mostly higher-income neighborhoods including parts of Coconut Grove,

511 Coral Gables, Pinecrest, and Key Biscayne (American Community Survey 2013; see

512 also Ackley et al. 2015b). Socio-economic factors influence surface temperatures

513 primarily through their impact on vegetation cover (Grove et al. 2006; Jenerette et

514 al. 2007; Boone et al. 2010); such that areas with dense, mature tree canopies will

515 produce relatively cooler microclimates suitable for $A$. cristatellus. These underlying 
516 effects of urban vegetation on available microclimates provide a mechanistic

517 understanding of the current distribution of A. cristatellus in Miami. Other studies of

518 urban and fragmented landscapes show species presence connected with other key

519 resources, such as prey availability (e.g., Sullivan et al. 2014), shelter availability

520 (e.g., Fischer et al. 2005), and structural habitat (e.g., Sarre et al. 1995; Garden et al.

521 2007; Santos et al. 2008) as well as urban development (e.g., Germaine and

522 Wakeling 2001). Future studies should test whether socio-economic factors are

523 correlated with vegetation and microclimates, and thus potentially useful for

524 predicting the spread of A. cristatellus in Miami.

526 Thermal microclimates

$527 \quad$ We found substantial temperature differences between copper lizard models

528 on open versus shaded trees (Fig. 3). Non-thermoregulating lizards would

529 experience a temperature difference of up to a $7.6^{\circ} \mathrm{C}$ in the morning $(1000 \mathrm{~h})$ and a

$5305.7^{\circ} \mathrm{C}$ in the afternoon $(1600 \mathrm{~h})$. Open trees, but not shaded ones, experienced

531 temperatures exceeding observed field $\mathrm{T}_{\mathrm{b}}$ for A. cristatellus in the summer in Miami

532 (Fig. 3). Denser overstory vegetation will produce relatively cooler microclimates

533 favorable for $A$. cristatellus in the city. Shade from vegetation cooled buildings up to

$53411.7^{\circ} \mathrm{C}$ during summer conditions in Toronto, Canada (Millward et al. 2014), and

535 shade from individual trees in city parks decreased average air temperatures by

$53610 \%$ and increased relative humidity by $18 \%$ in Thessaloniki, Greece (Georgi and

537 Zafiriadis 2006). Ackley et al. (2015a), using copper lizard models, found that

538 microclimates in areas with mesic landscaping were $5-10^{\circ} \mathrm{C}$ cooler than those in 
539 native xeric landscapes, even though the mean surface temperature of Phoenix,

540 Arizona, USA was $3^{\circ} \mathrm{C}$ warmer than the surrounding desert. Interestingly, surface

541 temperatures in Phoenix were related to vegetation during the daytime and the

542 proportion of paved area during the night (Buyantuyev and Wu 2010). Daytime

543 temperatures may limit activity or approach maximum thermal limits, whereas

544 nighttime temperatures likely influence metabolic costs during times of inactivity.

545 Whether the distribution of A. cristatellus in Miami is limited by daytime

546 temperatures driven by vegetation, nighttime temperatures related to impervious

547 surfaces, or both is a key question for future study.

$548 \quad$ Copper lizard model temperatures do not account for the ability of lizards to

549 thermoregulate. If suitably cool microhabitats were nearby, lizards in open areas

550 could behaviorally thermoregulate to preferred temperatures by shuttling between

551 warm and cool spots, at the cost of increased movement rates. The cost of

552 thermoregulation is predicted to be lower in more open sites because of the shorter

553 distance to sunny patches, which lowers the energetic cost of shuttling between sun

554 and shade (Huey 1974; Huey and Slatkin 1976; Huey and Webster 1976; Angilletta

555 2009). Accordingly, previous studies of $A$. cristatellus in Puerto Rico found that

556 lizards actively thermoregulate in open habitats, but thermoconform in less

557 variable, closed canopy habitats (Huey and Webster 1976). This versatility in

558 thermoregulatory behavior suggests that A. cristatellus might occupy both open and

559 closed canopy sites in Miami; however, A. cristatellus is generally restricted to

560 relatively closed canopy locations ( $<22 \%$ canopy openness; Fig. 4). 
Our results suggest at least two possible explanations for this pattern. The

562 first is that $A$. cristatellus uses relatively cooler microclimates strictly due to its

563 thermal requirements: open canopy areas in Miami may be too warm relative to the

564 preferred temperature and upper thermal limit of A. cristatellus, and thus not

565 suitable for this species (Fig. 3). A second possibility is that A. cristatellus is

566 excluded from warmer areas by the presence of $A$. distichus and A. sagrei, which

567 both occupy warmer thermal niches than A. cristatellus (Huey and Webster 1976;

568 Lee 1980; Gunderson and Leal 2012; Leal and Gunderson 2012; Kolbe et al. 2012,

569 2014; this study). The relative importance of these two factors on limiting the

570 spread of $A$. cristatellus in the Miami area is an open question. These hypotheses

571 need to be comprehensively evaluated by including sites where each species is

572 present in the absence of the other as well as locations where they coexist. The

573 importance of microclimates to competitive interactions between the species,

574 allowing coexistence or contributing to competitive exclusion, warrants further

575 investigation.

576 During the summer in Miami, shade from urban vegetation is expected to

577 produce microclimates closer to the preferred body temperature of $A$. cristatellus as

578 compared to more open areas (Fig. 3). Higher activity rates are predicted when

579 lizards are closer to their preferred temperature (Gunderson and Leal 2015),

580 allowing lizards to better forage, mate, defend their territories, and escape from

581 predators. Mean body temperatures for $A$. cristatellus in Miami $\left(28.8^{\circ} \mathrm{C}\right)$ and at low-

582 elevation, mesic sites in Puerto Rico $\left(\sim 29^{\circ} \mathrm{C}\right.$ from numerous sites; Huey and

583 Webster 1976; Hertz 1992a,b; Gunderson and Leal 2012) were similar to preferred 
584 temperatures for lizards from three locations in Puerto Rico (range $=29.0-29.6^{\circ} \mathrm{C}$;

585 Huey and Webster 1976; Fig. 3). This suggests that some aspects of the thermal

586 niche of A. cristatellus are conserved between introduced populations in South

587 Miami and their low-elevation source population in northeast Puerto Rico (Kolbe et

588 al. 2007). This similarity in field body temperatures occurs despite shifts in other

589 aspects of their thermal niche, specifically the introduced population in South Miami

590 rapidly acquired the ability to tolerate lower temperatures relative to its source

591 population in Puerto Rico (see Kolbe et al. 2012; Leal and Gunderson 2012).

592

593 Effect of species interactions on the spread of A. cristatellus

594 Interspecific interactions, primarily competition, are thought to be important

595 factors structuring both native and introduced Anolis lizard communities (Losos et

596 al. 1993; Losos 2009). Previous experimental studies of anoles have found effects

597 on abundance and structural habitat use consistent with interspecific competition

598 when species coexist (e.g., Pacala and Roughgarden 1982; Rummel and

599 Roughgarden 1985; Leal et al. 1998; Stuart et al. 2014). In accordance with

600 predictions based on ecological similarity (primarily perch height), A. cristatellus

601 presence showed the strongest negative association with $A$. sagrei, followed by $A$.

602 distichus, and in a few cases with A. carolinensis and A. equestris. Thus, ecological

603 similarity of interacting species may provide important information for predicting

604 patterns of establishment and range expansion dynamics for introduced species.

605 The negative relationship between A. cristatellus and A. sagrei in Miami may

606 be explained by resource competition and agonistic interference (Salzburg 1984, 
607 Losin 2012). When A. cristatellus was experimentally removed from plots five years

608 after its initial introduction in 1981, A. sagrei rapidly shifted back to the structural

609 habitat previously occupied by A. cristatellus - off the ground, on to trunks, and to

610 shadier sites (Salzburg 1984). We found consistent patterns, with A. cristatellus

611 occupying higher and broader perches as well as shadier microhabitats when

612 sympatric with A. sagrei. Additionally, A. cristatellus was far less abundant when

613 coexisting with congeners compared to when alone. However, competitive

614 interactions between A. cristatellus and A. sagrei may have changed over time with

615 their coexistence. Thirty years later, at the same site as Salzburg's experiment,

616 another removal experiment did not influence habitat use or body condition of these

617 two species (Losin 2012). Furthermore, A. sagrei lizards found sympatric with $A$.

618 cristatellus were less aggressive toward this species compared to A. sagrei from

619 allopartric populations (Losin 2012). Aggressive individuals facilitated the rapid

620 range expansion of western bluebirds in the northwestern U.S., but following

621 displacement of mountain bluebirds, their aggressive behavior decreased rapidly

622 (Duckworth \& Badyaev 2007). Given that A. sagrei is ubiquitous in Miami and $A$.

623 cristatellus is still spreading, the opportunity exists to study resource use and

624 aggression of $A$. sagrei before and after the arrival of $A$. cristatellus.

625

626 Summary

627 The occurrence of introduced A. cristatellus in Miami is strongly associated

628 with forest habitat - dense vegetation, high canopy cover and low impervious

629 surface - and the lack of congeners, particularly A. sagrei. Given the correlative 
630 nature of our analyses, it is difficult to tease apart the causal effects of urban

631 vegetation and species interactions for limiting the spread of $A$. cristatellus.

632 However, because A. sagrei already occupies nearly all habitats in Miami and forest

633 habitat is highly fragmented across the city, we predict that dispersal to forest

634 habitat will be the primary factor limiting future spread of A. cristatellus. Human-

635 mediated, sometimes long-distance, dispersal is likely to contribute to spread as

636 well as movement by diffusion through corridors of suitable habitats.

\section{Acknowledgments}

639

640 This research was supported by grants from the Harvard University Center for the

641 Environment to RTTF and JBL, and the National Geographic Society, National

642 Science Foundation (DEB-1354897) and University of Rhode Island Council for

643 Research to JJK. We thank Rick Stanley for help in the field, Matthew Girard for

644 producing maps of our study area, David Lee for assistance with tree identification,

645 and Neil Losin and Nathan Dappen for logistical support in Miami.

646 
647 Table 1. Variables recorded at each tree along transects designed to cross the 648 distributional boundary of A. cristatellus in the Miami metropolitan area. Tree 649 characteristics relate to the focal tree sampled and its surrounding vegetation. A 650 total of 1035 trees were sampled on 19 transects in five plots. Congener presence 651 refers to the four other species of Anolis lizards with distributions that overlap with 652 A. cristatellus in Miami.

653

\begin{tabular}{|c|c|}
\hline Variable & Description \\
\hline \multicolumn{2}{|l|}{ Tree characteristics: } \\
\hline Tree species & Species of tree \\
\hline Native/non-native & Native or non-native tree species \\
\hline Palm/non-palm & Palm or non-palm tree species \\
\hline Trunk number & $\begin{array}{l}\text { Number of trunks } \geq 10 \mathrm{~cm} \text { at } 1.35 \mathrm{~m} \text { height; } \\
\text { Single, double, or multiple ( }>2 \text { trunks) }\end{array}$ \\
\hline Bark texture & $\begin{array}{l}\text { Overlapping (overlapping protrusions covering the } \\
\text { trunk, such as palms covered with the bases of dead leaf } \\
\text { pedicles); shallow furrows (bark with furrows, gaps, or } \\
\text { cracks } \geq 0.5 \mathrm{~cm} \text { and no overlapping or flaking); deep } \\
\text { furrows (bark separating or flaking } \geq 0.75 \mathrm{~cm} \text { over an } \\
\text { area } \geq 2 \times 4 \mathrm{~cm} \text { ) or smooth (lacking any of the above } \\
\text { characteristics) }\end{array}$ \\
\hline Trunk diameter & Diameter $(\mathrm{cm})$ of trunk at $1.35 \mathrm{~m}$ height \\
\hline Canopy diameter & $\begin{array}{l}\text { Mean canopy diameter }(\mathrm{m}) \text { estimated from several } \\
\text { measurements of the radius of the canopy }\end{array}$ \\
\hline Distance to nearest plant & Distance $(\mathrm{m})$ to the nearest stem at $1.35 \mathrm{~m}$ height \\
\hline Distance to nearest tree & $\begin{array}{l}\text { Distance }(\mathrm{m}) \text { to the nearest tree with a diameter } \geq 30 \mathrm{~cm} \\
\text { at } 1.35 \mathrm{~m} \text { height }\end{array}$ \\
\hline Overstory canopy cover & $\begin{array}{l}\text { Mean percent overstory canopy cover both facing } \\
\text { towards and away from the road as measured using a } \\
\text { spherical densiometer }\end{array}$ \\
\hline
\end{tabular}

\section{Congener presence:}
A. carolinensis
Presence/absence of A. carolinensis
A. distichus Presence/absence of $A$. distichus
A. equestris Presence/absence of $A$. equestris A. sagrei Presence/absence of $A$. sagrei 
Table 2. GIS attributes derived from maps of forest fragmentation (NOAA 2010), percentage of human-made impervious surface (MRLC 2011), and variables recorded along transects.

\begin{tabular}{|c|c|}
\hline GIS Attribute & Description \\
\hline Trees per km & Number of trunks / Block length * 1000 \\
\hline Block canopy density & Number of trunks * Mean canopy diameter / Block length \\
\hline Canopy cover GIS & Proportion of a 5-m buffer around the block transects including pixels classified as any type of forest \\
\hline $\begin{array}{l}\text { Distance to nearest } \\
\text { patch forest }\end{array}$ & Distance $(\mathrm{m})$ from each point to the center of the nearest pixel of patch forest \\
\hline $\begin{array}{l}\text { Distance to nearest } \\
\text { block forest }\end{array}$ & $\begin{array}{l}\text { Distance }(\mathrm{m}) \text { from each point to the center of the nearest pixel of non-patch forest (i.e., either } \\
\text { perforated, edge or core forest) }\end{array}$ \\
\hline $\begin{array}{l}\text { Impervious surface } \\
\text { ( } 9 \text { pixels) }\end{array}$ & Average value of the 9 impervious raster pixels around each point ( $90 \mathrm{~m}$ by $90 \mathrm{~m}$ ) \\
\hline $\begin{array}{l}\text { Impervious surface } \\
(25 \text { pixels) }\end{array}$ & Average value of the 25 impervious raster pixels around each point $(150 \mathrm{~m}$ by $150 \mathrm{~m})$ \\
\hline
\end{tabular}


Table 3. Counts for the number of lizards present on surveyed trees $(n=1035)$ and the percent of trees occupied by the five Anolis species encountered on transects in Miami. Results for each of three surveys are shown for A) all data, B) sections of transects where A. cristatellus is present, and C) sections of transects where A. cristatellus is absent. The combined surveys column indicates whether a species was present on a tree in at least one of the three surveys; these data were used in analyses.

A)

1st survey

2nd survey

3rd survey

Combined surveys

Number of lizards

Number of lizards

Number of lizards

Number of lizards

\begin{tabular}{|c|c|c|c|c|c|c|c|c|c|c|c|c|c|c|c|c|c|c|c|c|c|}
\hline Species & $\mathbf{0}$ & 1 & 2 & 3 & $\geq 4$ & $\%$ & $\mathbf{0}$ & 1 & 2 & 3 & $\geq 4$ & $\%$ & $\mathbf{0}$ & 1 & 2 & 3 & $\geq 4$ & $\%$ & Absent & Present & $\%$ \\
\hline A. carolinensis & 986 & 45 & 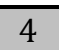 & 0 & 0 & 4.7 & 967 & 64 & 3 & 1 & 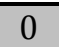 & 6.6 & 940 & 87 & - & 1 & 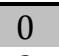 & 9.1 & 856 & 179 & 17.3 \\
\hline A. $\mathrm{Cl}$ & 895 & 107 & 23 & 7 & 3 & 13 & 873 & 11 & 29 & 12 & & 10 & 8 & 115 & 17 & 5 & & 13 & 81 & 254 & .5 \\
\hline A. distichus & 865 & 133 & 28 & 8 & 1 & 16.4 & 829 & 142 & 50 & 10 & & 19 & 78 & 170 & 5 & 16 & & 23.9 & 63 & 399 & 38.6 \\
\hline A. eq & 1029 & 6 & 0 & 0 & 0 & 0.6 & 1029 & 6 & 0 & 0 & 0 & 0.6 & 1013 & 6 & & 0 & 0 & 0.6 & 1018 & 17 & 1.6 \\
\hline A. sagrei & 838 & 135 & 43 & 10 & 9 & 19.0 & 812 & 157 & 47 & 8 & 11 & 21.5 & 831 & 142 & 36 & 11 & 14 & 19.6 & 660 & 375 & 36.2 \\
\hline
\end{tabular}

B)

1st survey

2nd survey

3rd survey

Combined surveys

\begin{tabular}{|c|c|c|c|c|c|c|c|c|c|c|c|c|c|c|c|c|c|c|c|c|c|}
\hline & \multicolumn{6}{|c|}{ Number of lizards } & \multicolumn{5}{|c|}{ Number of lizards } & & \multicolumn{5}{|c|}{ Number of lizards } & \multicolumn{4}{|c|}{ Number of lizards } \\
\hline Species & $\mathbf{0}$ & 1 & 2 & 3 & $\geq 4$ & $\%$ & $\mathbf{0}$ & 1 & 2 & 3 & $\geq 4$ & $\%$ & $\mathbf{0}$ & 1 & 2 & 3 & $\geq 4$ & $\%$ & Absent & Present & $\%$ \\
\hline A. carolinensis & 554 & 25 & $\overline{4}$ & 0 & 0 & 5.0 & 553 & 30 & 0 & 0 & 0 & 5.1 & 539 & 41 & 2 & 1 & 0 & 7.5 & 492 & 91 & 15.6 \\
\hline A. cristatellus & 443 & 107 & 23 & 7 & 3 & 24.0 & 421 & 119 & 29 & 12 & 2 & 27.8 & 443 & 115 & 17 & 5 & 3 & 24.0 & 329 & 254 & 43.6 \\
\hline A. distichus & 495 & 70 & 15 & 2 & 1 & 15.1 & 483 & 72 & 23 & 4 & 1 & 17.2 & 476 & 78 & 22 & 4 & 3 & 18.4 & 383 & 200 & 34.3 \\
\hline A. equestris & 578 & 5 & 0 & 0 & 0 & 0.9 & 579 & 4 & 0 & 0 & 0 & 0.7 & 579 & 4 & 0 & 0 & 0 & 0.7 & 571 & 12 & 2.1 \\
\hline A. sagrei & 492 & 66 & 17 & 3 & 5 & 15.6 & 496 & 61 & 16 & 4 & 6 & 14.9 & 512 & 51 & 11 & 4 & 5 & 12.2 & 428 & 155 & 26.6 \\
\hline
\end{tabular}

C)

1st survey

2nd survey

3rd survey

Combined surveys

Number of lizards

Number of lizards

Number of lizards

Number of lizards

\begin{tabular}{|c|c|c|c|c|c|c|c|c|c|c|c|c|c|c|c|c|c|c|c|c|c|}
\hline Species & $\mathbf{0}$ & 1 & 2 & 3 & $\geq 4$ & $\%$ & $\mathbf{0}$ & 1 & 2 & 3 & $\geq 4$ & $\%$ & 0 & 1 & 2 & 3 & $\geq 4$ & $\%$ & Absent & Present & $\%$ \\
\hline A. carolinensis & 432 & 20 & 0 & 0 & 0 & 4.4 & 414 & 34 & 3 & 1 & 0 & 8.4 & 401 & 46 & 4 & 0 & 0 & 11.1 & 364 & 88 & 19.5 \\
\hline A. cristatellus & & & & & & & & & & & & & & & & & & & & & 0.0 \\
\hline A. distichus & 370 & 63 & 13 & 6 & 0 & 18.1 & 346 & 70 & 27 & 6 & 3 & 23.5 & 311 & 92 & 32 & 12 & 4 & 31.0 & 253 & 199 & 44.0 \\
\hline A. equestris & 451 & 1 & 0 & 0 & 0 & 0.2 & 450 & 2 & 0 & 0 & 0 & 0.4 & 434 & 2 & 0 & 0 & 0 & 0.5 & 447 & 5 & 1.1 \\
\hline A. sagrei & 346 & 69 & 26 & 7 & 4 & 23.5 & 316 & 96 & 31 & 4 & 5 & 30.1 & 319 & 91 & 25 & 7 & 9 & 29.3 & 232 & 220 & 48.7 \\
\hline
\end{tabular}


Table 4. Inferential statistics based on tree characteristics showing the most likely generalized linear models for presenceabsence of A. cristatellus when A) dividing sections of transects into areas with A. cristatellus present versus absent (two groups), B) comparing the presence versus absence of $A$. cristatellus on all trees pooled, and C) comparing the presence versus absence of $A$. cristatellus on trees within only the sections of transects with A. cristatellus present, and for abundance of $A$. cristatellus for D) all trees pooled and E) within only the sections of transects with A. cristatellus present.

\section{A)}

\begin{tabular}{lcccr}
\hline Effect & Effect df & Error df & $\boldsymbol{Z}$ & $\boldsymbol{P}$ \\
Trunk diameter & 1 & 1031 & 0.09 & 0.06 \\
Canopy diameter & 1 & 1030 & 0.13 & 0.16 \\
Distance to nearest plant & 1 & 1029 & -0.53 & $<0.0001$ \\
Overstory canopy cover & 1 & 1028 & 0.41 & $<0.0001$ \\
\hline
\end{tabular}

Note: second best model $\triangle \mathrm{AIC}=0.8$; including the Distance to Nearest Tree effect; $\mathrm{P}=0.27$.

B)

\begin{tabular}{lrrrr}
\hline Effect & Effect df & Error df & $\boldsymbol{Z}$ & $\boldsymbol{P}$ \\
Canopy diameter & 1 & 1031 & 0.27 & $<0.001$ \\
Distance to nearest plant & 1 & 1030 & -0.86 & $<0.0001$ \\
Distance to nearest tree & 1 & 1029 & -0.20 & 0.05 \\
Overstory canopy cover & 1 & 1028 & 0.90 & $<0.0001$ \\
\hline
\end{tabular}

Note: second best model $\triangle \mathrm{AIC}=1.6$; including the Trunk Diameter effect; $\mathrm{P}=0.53$.

C)

\begin{tabular}{lrrrr}
\hline Effect & Effect df & Error df & $\boldsymbol{Z}$ & $\boldsymbol{P}$ \\
Trunk diameter & 1 & 580 & 0.51 & $<0.0001$ \\
Distance to nearest plant & 1 & 579 & -0.87 & $<0.0001$ \\
Overstory canopy cover & 1 & 578 & 0.72 & $<0.0001$ \\
\hline
\end{tabular}


Note: second best model $\Delta \mathrm{AIC}=1.37$; including the Distance to Nearest Tree effect; $\mathrm{P}=0.43$.

D)

\begin{tabular}{lrrrr}
\hline Effect & Effect df & Error df & $\boldsymbol{Z}$ & $\boldsymbol{P}$ \\
Trunk diameter & 1 & 1031 & 4.46 & $<0.0001$ \\
Canopy diameter & 1 & 1030 & 2.24 & 0.03 \\
Distance to nearest plant & 1 & 1029 & -5.71 & $<0.0001$ \\
Overstory canopy cover & 1 & 1028 & 3.65 & $<0.0001$ \\
\hline
\end{tabular}

Note: second best model $\triangle \mathrm{AIC}=1.23$; including the Distance to Nearest Tree effect; $\mathrm{P}=0.38$.

E)

\begin{tabular}{lcccr}
\hline Effect & Effect df & Error df & $\boldsymbol{Z}$ & $\boldsymbol{P}$ \\
\hline Trunk diameter & 1 & 579 & 0.68 & $<0.0001$ \\
Distance to nearest plant & 1 & 580 & -0.34 & $<0.0001$ \\
Overstory canopy cover & 1 & 578 & 0.32 & $<0.0001$ \\
\hline
\end{tabular}

Note: second best model $\triangle \mathrm{AIC}=1.59$; including the Canopy Diameter effect; $\mathrm{P}=0.52$. 
Table 5. Inferential statistics for presence-absence of $A$. cristatellus showing the most likely generalized linear models when A) comparing street blocks with $A$. cristatellus present versus absent (n=93) and $\mathrm{B}$ ) comparing the presence versus absence of $A$. cristatellus in $30 \times 30$ pixels $(\mathrm{n}=839)$. Selection of most favored models was supported by a likelihood ratio test against reduced models containing only the intercept term $\left(\mathrm{A}: \chi^{2}=51.19, P<0.0001\right.$; $\left.\mathrm{B}: \chi^{2}=203.24, P<0.0001\right)$.

\begin{tabular}{lclcc} 
A) & Effect df & Error df & $\boldsymbol{Z}$ & $\boldsymbol{P}$ \\
\hline Effect & 1 & 92 & -1.799 & 0.07 \\
Distance to nearest plant & 1 & 92 & 2.007 & 0.05 \\
Mean overstory canopy cover & 1 & 92 & 1.865 & 0.06 \\
Trees per km & 1 & 92 & -2.386 & 0.02 \\
\hline \% Impervious-raster & 1
\end{tabular}

Note: second best model $\triangle \mathrm{AIC}=1.25$; including the Distance to Nearest Tree effect; $P=0.39$.

\begin{tabular}{lcccc} 
B) & Effect df & Error df & $\boldsymbol{Z}$ & $\boldsymbol{P}$ \\
\hline Effect & 1 & 838 & 8.752 & $<0.0001$ \\
Distance to nearest patch forest & 1 & 838 & -6.446 & $<0.0001$ \\
Distance to nearest block forest & 1 & 838 & -2.947 & $<0.01$ \\
Impervious surface (1 pixel) & 1 & 838 & -4.318 & $<0.0001$ \\
\hline Impervious surface (25 pixels) & 1 &
\end{tabular}

Note: second best model $\triangle \mathrm{AIC}=1.06$; including the Forest_Class effect; $P=0.39$. 
Table 6. Results of likelihood ratio tests to determine whether the presence-absence of $A$. cristatellus on trees in Miami was related to the presence-absence of each of its four congeners. We combined trees on transects from each of the five plots analyzing A) all trees pooled and B) only trees from sections of transects with A. cristatellus present.

A)

\begin{tabular}{lccccccccc}
\hline & & A. carolinensis & & A. distichus & \multicolumn{3}{c}{ A. sagrei } & \multicolumn{3}{c}{ A. equestris } \\
\hline Plot & $\mathbf{N}$ & $\mathbf{X}^{\mathbf{2}}$ & $\mathbf{P}$ & $\mathbf{X}^{\mathbf{2}}$ & $\mathbf{P}$ & $\mathbf{X}^{\mathbf{2}}$ & $\mathbf{P}$ & $\mathbf{X}^{\mathbf{2}}$ & $\mathbf{P}$ \\
Charles & 163 & 5.71 & 0.02 & 17.92 & $<0.0001$ & 18.90 & $<0.0001$ & 0.26 & 0.61 \\
Le Jeune & 125 & 0.25 & 0.61 & 0.27 & 0.60 & 4.21 & 0.04 & 7.32 & $<0.01$ \\
Ludlum & 270 & 0.59 & 0.44 & 1.32 & 0.25 & 7.81 & $<0.01$ & 0.03 & 0.86 \\
Maynada & 137 & 6.29 & 0.01 & 2.23 & 0.14 & 3.68 & 0.06 & 0.74 & 0.39 \\
SW 104 & 340 & 0.56 & 0.45 & 0.85 & 0.36 & 28.91 & $<0.0001$ & 0.76 & 0.38 \\
All Plots Combined & 1035 & 2.38 & 0.12 & 7.21 & $<0.01$ & 59.19 & $<0.0001$ & 2.31 & 0.13 \\
\hline
\end{tabular}

B)

\begin{tabular}{lccccccccc}
\hline & \multicolumn{3}{c}{ A. carolinensis } & \multicolumn{1}{c}{ A. distichus } & \multicolumn{3}{c}{ A. sagrei } & \multicolumn{3}{c}{ A. equestris } \\
\hline Plot & $\mathbf{N}$ & $\mathbf{X}^{\mathbf{2}}$ & $\mathbf{P}$ & $\mathbf{X}^{\mathbf{2}}$ & $\mathbf{P}$ & $\mathbf{X}^{\mathbf{2}}$ & $\mathbf{P}$ & $\mathbf{X}^{\mathbf{2}}$ & $\mathbf{P}$ \\
Charles & 87 & 1.12 & 0.29 & 2.24 & 0.13 & 0.68 & 0.41 & 0.10 & 0.75 \\
Le Jeune & 80 & 0.42 & 0.52 & 0.13 & 0.72 & 1.95 & 0.16 & 4.60 & 0.03 \\
Ludlum & 215 & 0.00 & 0.99 & 0.39 & 0.53 & 7.52 & $<0.01$ & 0.04 & 0.85 \\
Maynada & 48 & 5.55 & 0.02 & 5.35 & 0.02 & 1.70 & 0.19 & 1.32 & 0.25 \\
SW 104 & 153 & 0.20 & 0.65 & 0.53 & 0.47 & 3.34 & 0.07 & 2.77 & 0.10 \\
All Plots Combined & 583 & 0.71 & 0.40 & 1.58 & 0.21 & 22.23 & $<0.0001$ & 1.08 & 0.30 \\
\hline
\end{tabular}




\section{Figures Captions}

Fig. 1. Location of our study area in metropolitan Miami-Dade County of southeast Florida showing the core area in South Miami and sampling locations for $A$. cristatellus. Inset photo of a male A. cristatellus perched on a brick wall (J. Kolbe).

Fig. 2. Maps of a portion of the core area near Coconut Grove showing A. cristatellus presence and absence points and A) the four types of forest fragments and B) the percentage of impervious surface within $75 \mathrm{~m}$.

Fig. 3. Mean temperatures for copper lizard models placed on the trunks of two trees, one with an open canopy and the other with a shaded canopy, in each cardinal direction. Points are hourly means collected over a 3.5-day period in July 2014 (error bars are omitted for clarity). Patterned shading (gray) shows the range of field $\mathrm{T}_{\mathrm{b}}$ for A. cristatellus in Miami during each hour from 0800-1400 from this study as well as the preferred $\mathrm{T}_{\mathrm{b}}$ (light gray) and the critical thermal maximum (dotted line) of $A$. cristatellus measured for populations from Puerto Rico (Huey and Webster 1976).

Fig. 4. Relationships between lizard field body temperature or copper lizard model temperature and significant covariates from the ANCOVA: a) canopy openness, b) air temperature, and c) time of day for A. cristatellus (black circles), A. sagrei (white circles), and copper lizard models at random locations (gray circles) in South Miami. Separate slopes are shown for the significant temperature by canopy openness interaction. 
Fig. 1.

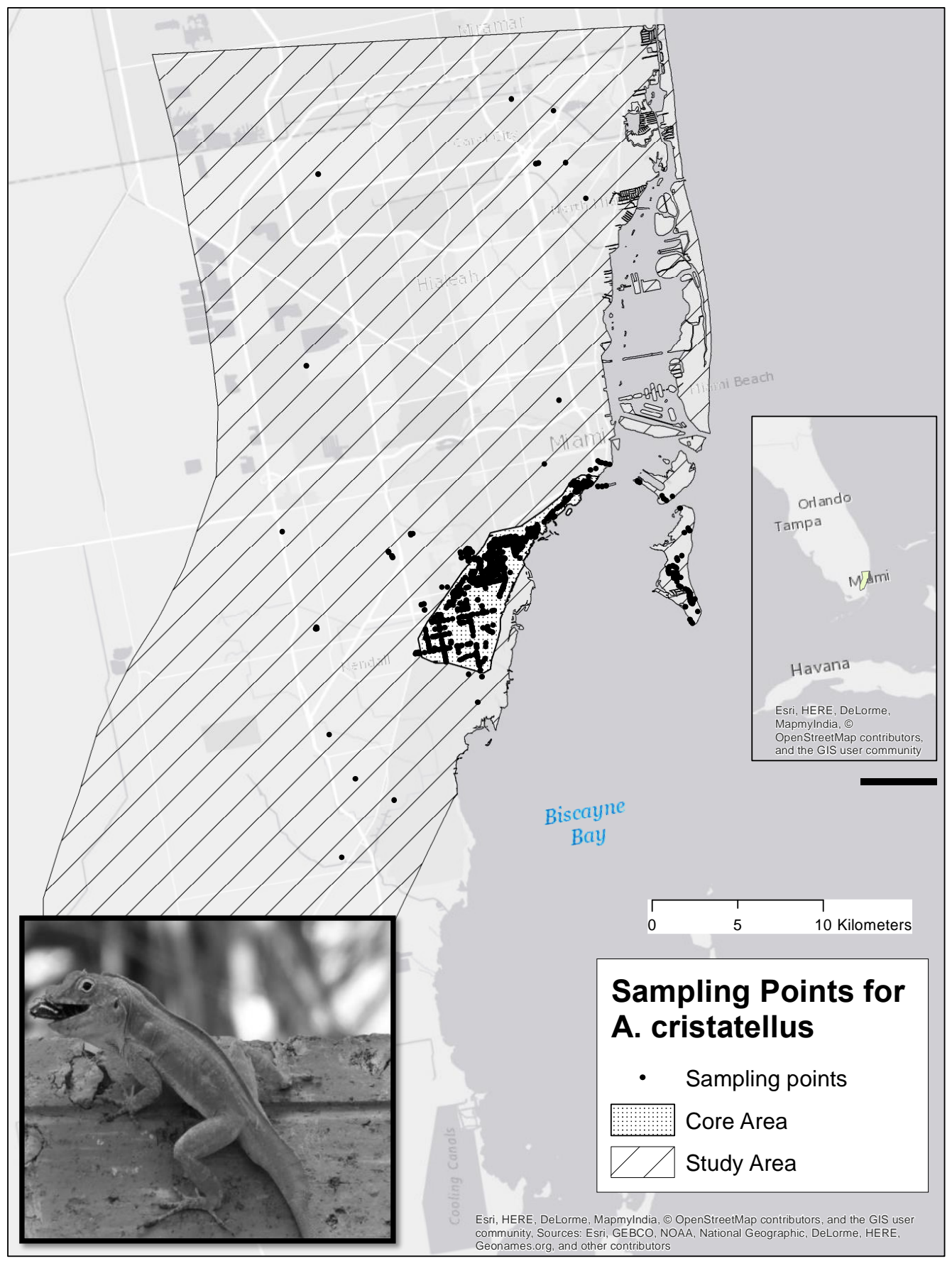


Fig. 2.

\section{A)}

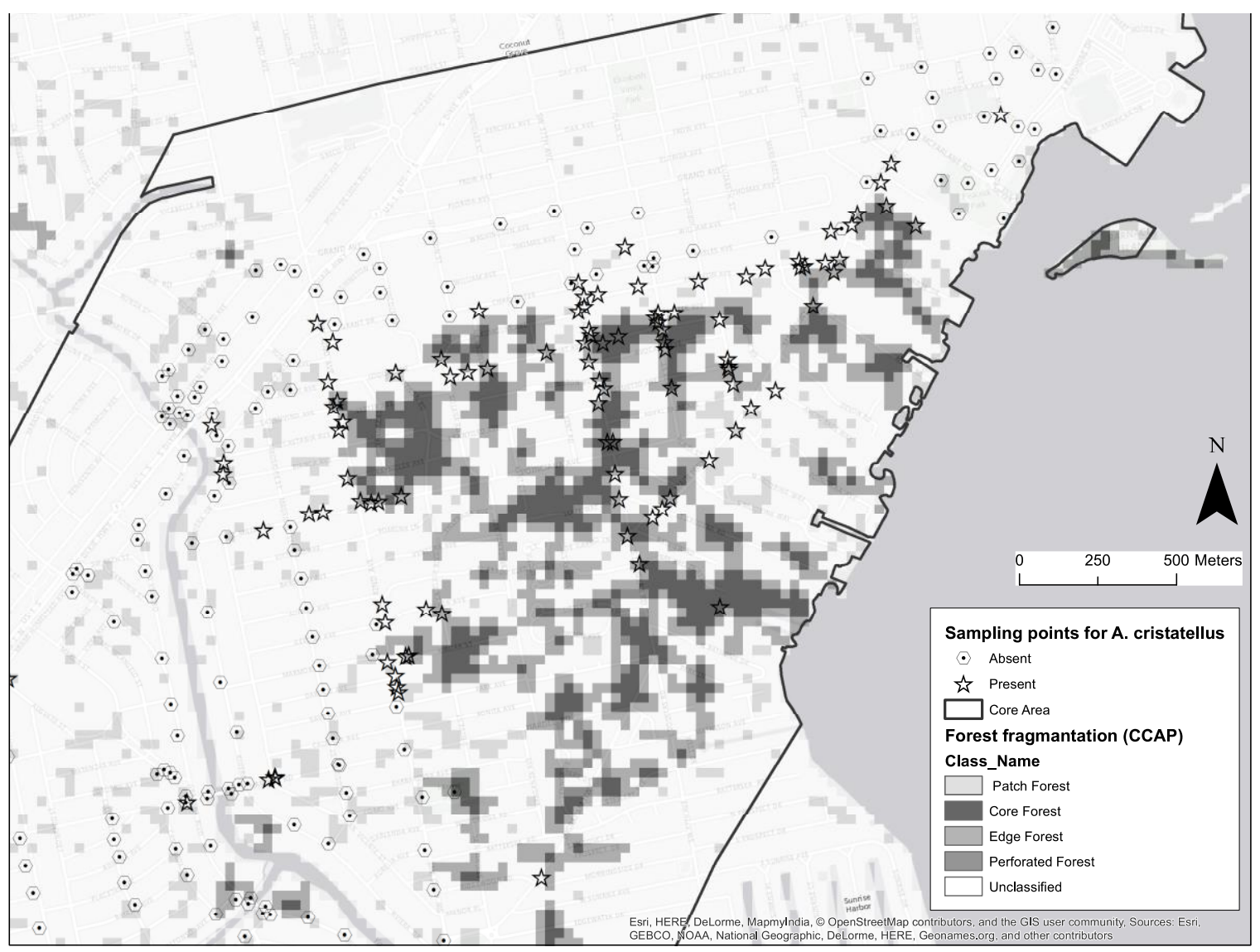


B)

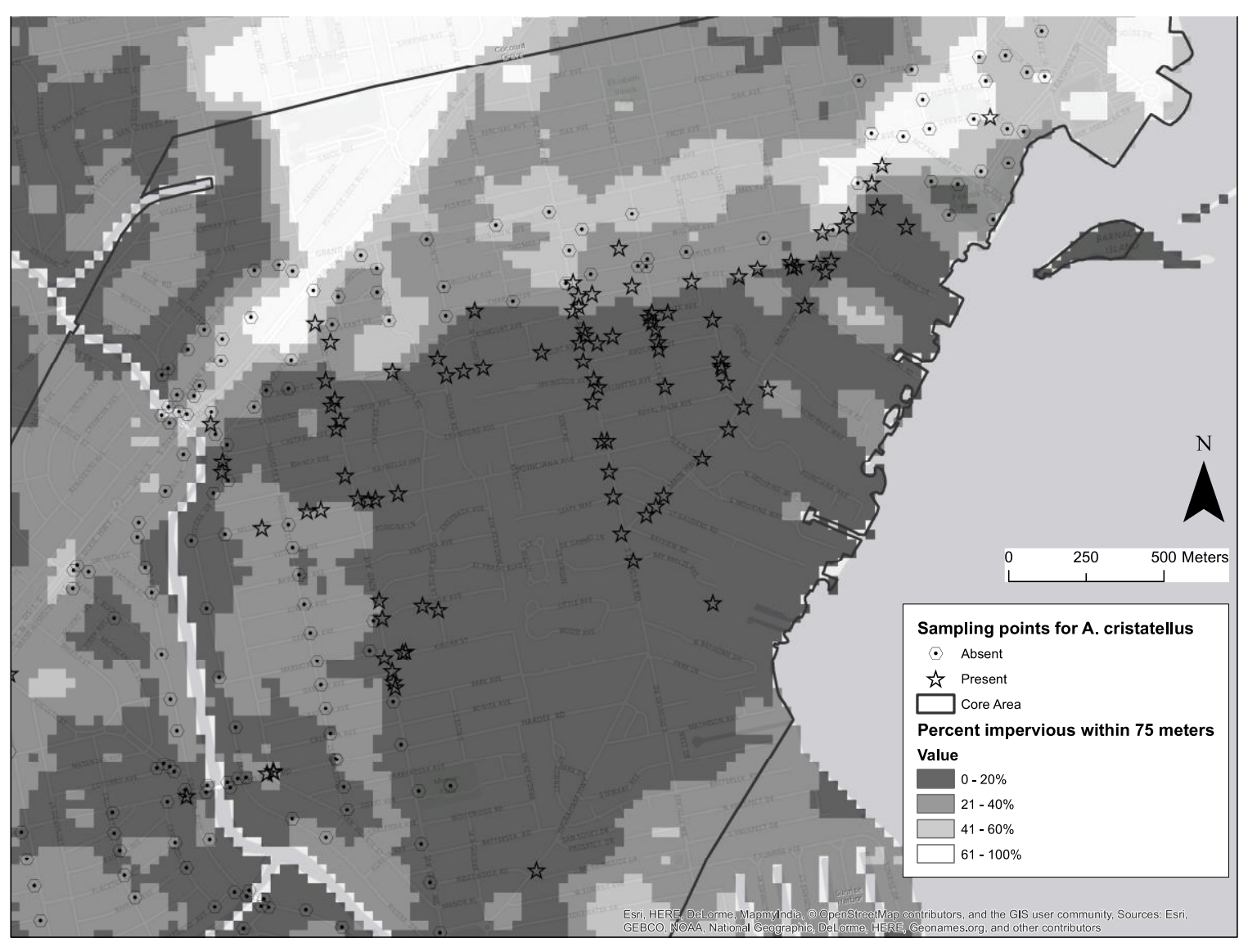


Fig. 3.

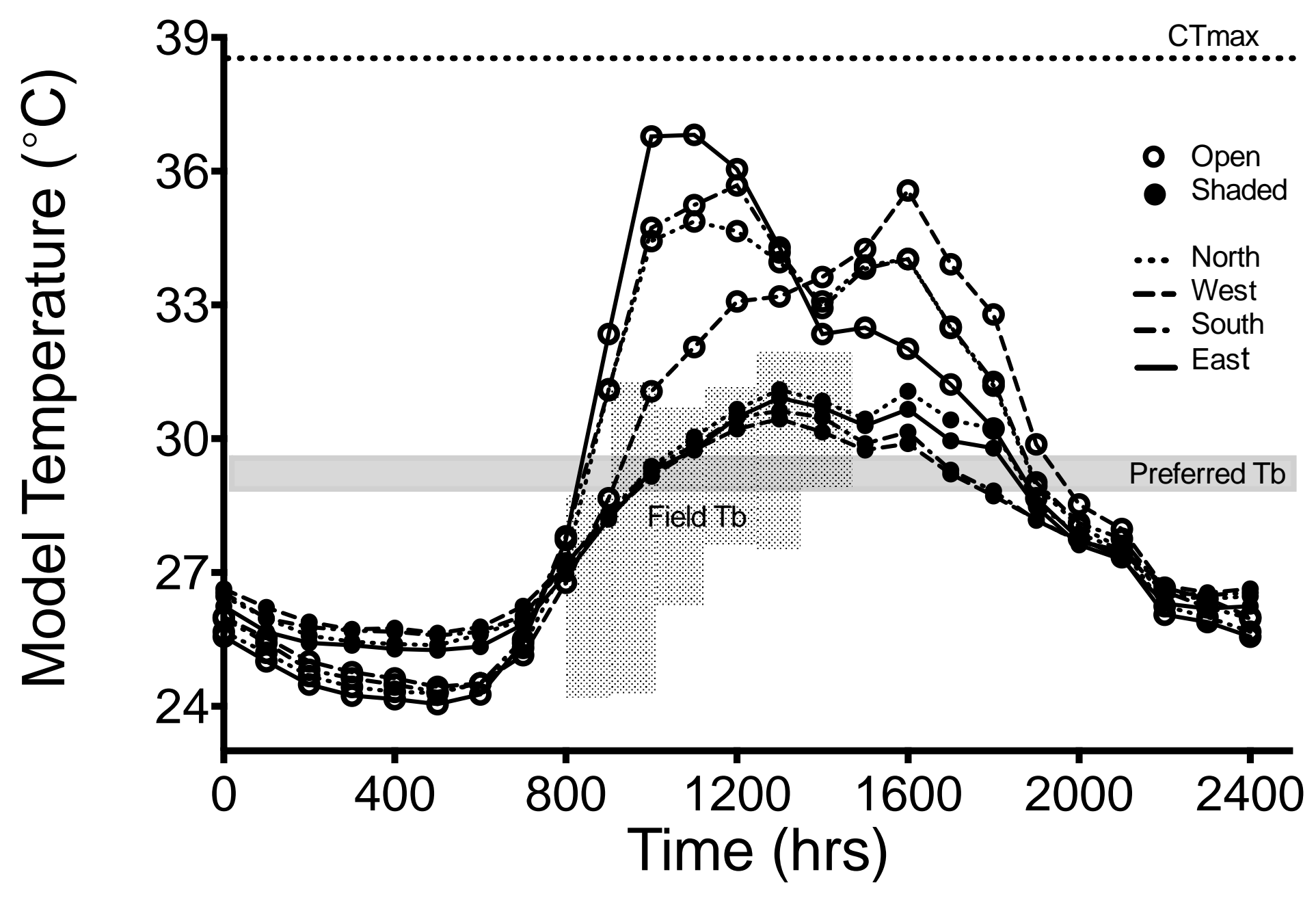


Fig. 4.

a

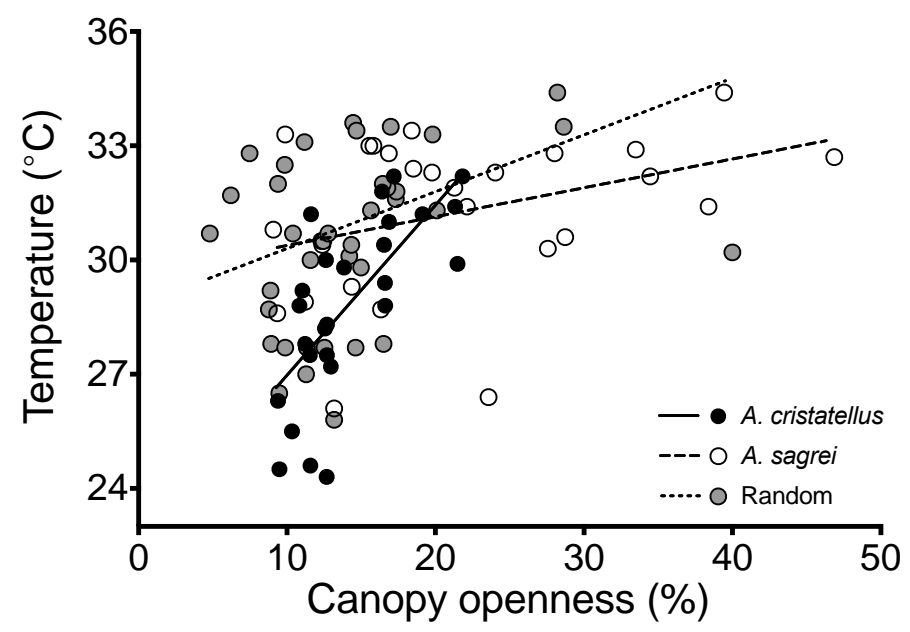

b

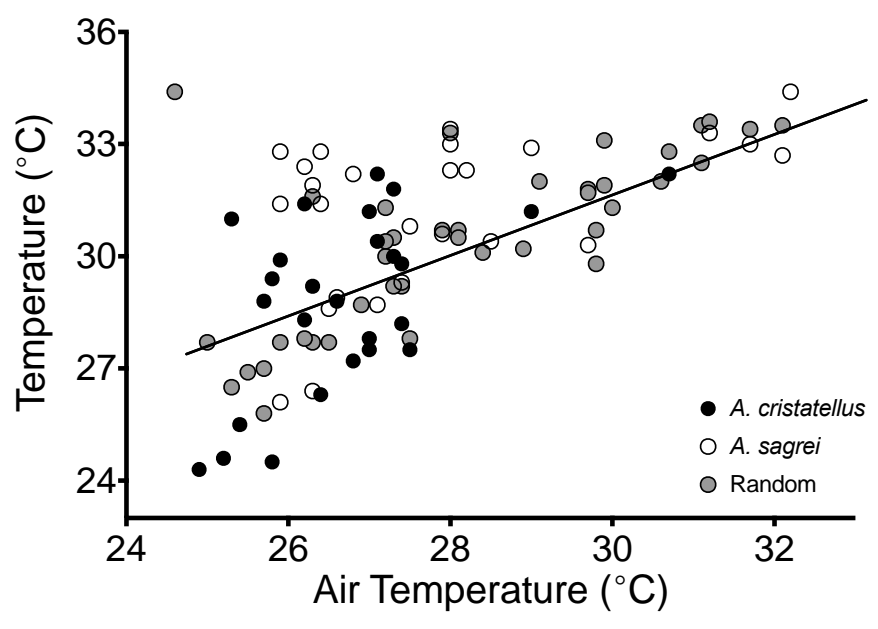

C

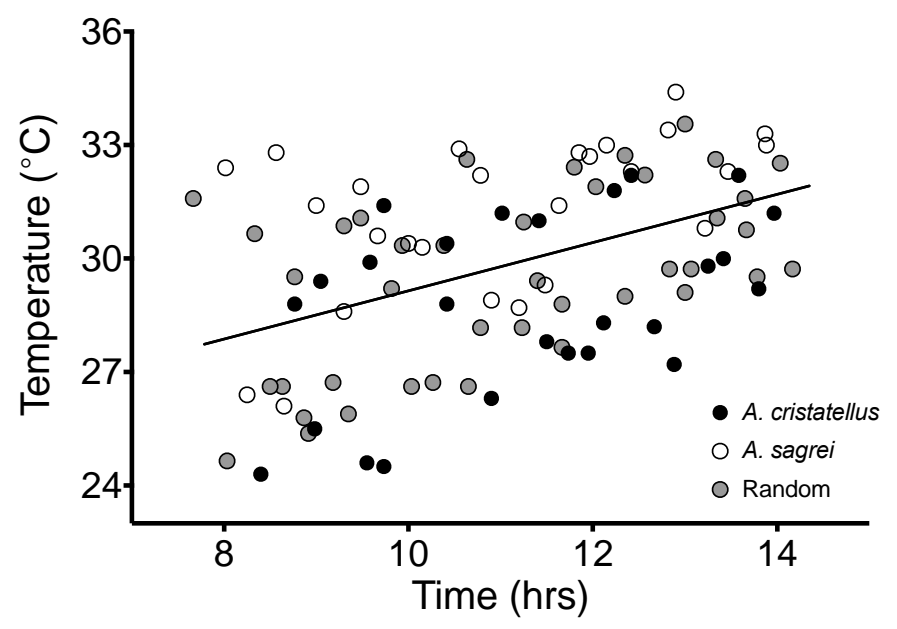




\section{References}

Ackley JW, Angilletta MJ Jr., DeNardo D, Sullivan B, Wu J (2015a) Urban heat island mitigation strategies and lizard thermal ecology: landscaping can quadruple potential activity time in an arid city. Urban Ecosyst DOI 10.1007/s11252-0150460-x.

Ackley JW, Wu J, Angilletta MJ Jr., Myint SW, Sullivan B (2015b) Rich lizards: how affluence and land cover influence the diversity and abundance of desert reptiles persisting in an urban landscape. Biol Conserv 182:87-92.

Akaike H (1974) A new look at the statistical model identification. IEEE Transactions on Automatic Control 19:716-723.

Akbari H, Pomerantz M, Taha H (2001) Cool surfaces and shade trees to reduce energy use and improve air quality in urban areas. Solar Energy 70:295-310.

American Community Survey (2013) United States Census Bureau. Available from http://www.census.gov (accessed August 2015)

Anderson L, Burgin S (2008) Patterns of bird predation on reptiles in small woodland remnant edges in peri-urban north-western Sydney, Australia. Landscape Ecol 23:1039-1047.

Angilletta MJ Jr (2009) Thermal adaptation: a theoretical and empirical synthesis. Oxford University Press, Oxford

Arnfield AJ (2003) Two decades of urban climate research: a review of turbulence, exchanges of energy and water, and the urban heat island. Int J Climatol 23:1-26.

Bartlett RD, Bartlett PP (1999) A field guide to Florida reptiles and amphibians. Gulf Publishing, Houston.

Bonnington C, Gaston KJ, Evans KL (2014) Squirrels in suburbia: influence of urbanisation on the occurrence and distribution of a common exotic mammal. Urban Ecosyst 17:533-546.

Boone CG, Cadenasso ML, Grove JM, Schwarz K, Buckley GL (2010) Landscape, vegetation characteristics, and group identity in an urban and suburban watershed: why the 60s matter. Urban Ecosyst 13:255-271.

Broennimann O, Fitzpatrick MC, Pearman PB, Petitpierre B, Pellissier L, Yoccoz NG, Thuiller W, Fortin M-J, Randin C, Zimmermann NE, Graham CH, Guisan A (2012) Measuring ecological niche overlap from occurrence and spatial environmental data. Global Ecol Biogeo 21:481-497. 
Buyantuyev A, Wu J (2010) Urban heat islands and landscape heterogeneity: linking spatiotemporal variations in surface temperatures to land-cover and socioeconomic patterns. Landscape Ecol 25:17-33.

Cadenasso ML, Pickett STA, Schwarz K (2007) Spatial heterogeneity in urban ecosystems: reconceptualizing land cover and a framework for classification. Front Ecol Environ 5:80-88.

Case TJ, Bolger DT, Petren K (1994) Invasions and competitive displacement among house geckos in the Tropical Pacific. Ecology 75:464-477.

Chen WY, Jim CY (2008) Assessment and valuation of the ecosystem services provided by urban forests. In: Ecology, planning, and management of urban forests international perspective. Springer, New York, pp 53-83.

Corn MJ (1971) Upper thermal limits and thermal preferenda for three sympatric species of Anolis. J Herpetol 5:17-21.

Crump ML, Scott NJ Jr (1994) Visual encounter surveys, p. 84-92. In: Measuring and Monitoring Biological Diversity: Standard Methods for Amphibians. W. R. Heyer, M. A. Donnelly, R. W. McDiarmid, L. A. C. Hayek, and M. S. Foster (eds.). Smithsonian Institution Press, Washington, D.C.

Davis MA (2009) Invasion Biology. Oxford University Press.

Duckworth RA, Badyaev AV (2007) Coupling of dispersal and aggression facilities the rapid range expansion of a passerine bird. PNAS 104:15017-15022.

Forman RTT (2014) Urban Ecology. Cambridge University Press.

Fischer J, Lindenmayer DB, Barry S, Flowers E (2005) Lizard distribution patterns in the Tumut fragmentation "Natural Experiment" in south-eastern Australia. Biol Conserv 123:301-315.

Frazer GW, Canham CD, Lertzman KP (1999) Gap Light Analyzer (GLA), Version 2.0: Imaging software to extract canopy structure and gap light transmission indices from true-colour fisheye photographs, users manual and program documentation. Copyright (C) 1999: Simon Fraser University, Burnaby, British Columbia, and the Institute of Ecosystem Studies, Millbrook, New York.

Garden JG, McAlpine CA, Possingham HP, Jones DN (2007) Habitat structure is more important than vegetation composition for local-level management of native terrestrial reptile and small mammal species living in urban remnants: a case study from Brisbane, Australia. Austral Ecol 32:669-685. 
Georgi NJ, Zafiriadis K (2006) The impact of park trees on microclimate in urban areas. Urban Ecosyst 9:195-209.

Germaine SS, Wakeling BF (2001) Lizard species distributions and habitat occupation along an urban gradient in Tucson, Arizona, USA. Biol Conserv 97:229237.

Grove JM, Troy AR, O'Neil-Dunne JPM, Burch WR, Cadenasso ML, Pickett STA (2006) Characterization of households and its implications for the vegetation of urban ecosystems. Ecosystems 9:578-597.

Gunderson AR, Leal M (2012) Geographic variation in vulnerability to climate warming in a tropical Caribbean lizard. Funct Ecol 26:783-793.

Gunderson AR, Leal M (2015) Patterns of thermal constraint on ectotherm activity. Am Nat 185: In press.

Hamdi R, Schayes G (2008) Sensitivity study of the urban heat island intensity to urban characteristics. Int J Climatol 28:973-982.

Hines JE (2006) PRESENCE - Software to estimate patch occupancy and related parameters. USGS-PWRC http://www.mbr-pwrc.usgs.gov/software/presence.html.

Huang L, Li J, Zhao D, Ahu J (2008) A fieldwork study on the diurnal changes of urban microclimate in four types of ground cover and urban heat island of Nanjing, China. Building and Environ 43:7-17.

Hertz PE (1992) Temperature regulation in Puerto Rican Anolis lizards: a field test using null hypotheses. Ecology 73:1405-1417.

Huey RB (1974) Behavioral thermoregulation in lizards: importance of associated costs. Science 184:1001-1003.

Huey RB, Webster TP (1976) Thermal biology of Anolis lizards in a complex fauna: the cristatellus group on Puerto Rico. Ecology 57:985-994.

Huey RB, Slatkin M (1976) Cost and benefits of lizard thermoregulation. Quart Rev Biol 51:363-384.

Irschick DJ, Carlisle E, Elstrott J, Ramos M, Buckley C, Vanhooydonck B, Meyers J, Herrell A (2005) A comparison of habitat use, morphology, clinging performance and escape behaviour among two divergent green anole lizard (Anolis carolinensis) populations. Biol J Linnean Soc 85:223-234. 
Jenerette GD, Harlan SL, Brazel A, Jones N, Larsen L, Stefanov WL (2007) Regional relationships between surface temperature, vegetation, and human settlement in a rapidly urbanizing ecosystem. Landscape Ecol 22:353-365.

Kolbe JJ, Glor RE, Schettino LR, Lara AC, Larson A, Losos JB (2007) Multiple sources, admixture, and genetic variation in introduced Anolis lizard populations. Conserv Biol 21:1612-1625.

Kolbe JJ, Colbert PL, Smith BE (2008) Niche relationships and interspecific interactions in Antiguan lizard communities. Copeia 2008:261-272.

Kolbe JJ, VanMiddlesworth PS, Losin N, Dappen N, Losos JB (2012) Climatic niche shift predicts thermal trait response in one but not both introductions of the Puerto Rican lizard Anolis cristatellus to Miami, Florida, USA. Ecol Evol 2: 1503-1516.

Kolbe JJ, Ehrenberger JC, Moniz HA, Angilletta MJ (2014) Physiological Variation among Invasive Populations of the Brown Anole (Anolis sagrei). Physiol Biochem Zool 87:92-104.

Kolbe JJ, Battles AC, Avilés-Rodríguez KJ (2015) City slickers: poor performance does not deter Anolis lizards from using artificial substrates in human-modified habitats. Funct Ecol doi: 10.1111/1365-2435.12607

Kraus F (2009) Alien reptiles and amphibians: a scientific compendium and analysis. Springer.

Leal M, Gunderson AR (2012) Rapid change in the thermal tolerance of a tropical lizard. Am Nat 180:815-822.

Leal M, Rodríguez-Robles JA, Losos JB (1998) An experimental study of interspecific interactions between two Puerto Rican Anolis lizards. Oecologia 117:273-278.

Lee JC (1980) Comparative thermal ecology of two lizards. Oecologia 44:171-176.

Lever C (2003) Naturalized reptiles and amphibians of the world. Oxford University Press.

Liu X, Li X, Liu Z, Tingley R, Kraus F, Guo Z, Li Y (2014) Congener diversity, topographic heterogeneity and human-assisted dispersal predict spread rates of alien herpetofauna at a global scale. Ecol Lett 17:821-829.

Lockwood JL, Hoopes MF, Marchetti MP (2007) Invasion Ecology. Blackwell Publishing. 
Losin NJE (2012) The evolution and ecology of interspecific territoriality: studies of Anolis lizards and North American wood-warblers. Dissertation. University of California Los Angeles.

Losos JB (1994) Integrative approaches to evolutionary ecology: Anolis lizards as model systems. Ann Rev Ecol Syst 25:467-493.

Losos JB (2009) Lizards in an Evolutionary Tree: Ecology and Adaptive Radiation of Anoles. University of California Press, Berkeley.

Losos JB, Marks JC, Schoener TW (1993) Habitat use and ecological interactions of an introduced and a native species of Anolis lizard on Grand Cayman. Oecologia 95:525-532.

Luck GW, Smallbone LT, O'Brien R (2009) Socio-economics and vegetation change in urban ecosystems: patterns in space and time. Ecosystems 12:604-620.

MacKenzie DI, Nichols JD, Lachman GB, Droege S, Royle JA, Langtimm CA (2002) Estimating site occupancy rates when detection probabilities are less than one. Ecology 83:2248-2255.

Marnocha E, Pollinger J, Smith TB (2011) Human-induced morphological shifts in an island lizard. Evol Appl 4:388-396.

Martin CA, Warren PS, Kinzig AP (2004) Neighborhood socioeconomic status is a usefull predictor of perennial landscape vegetation in residential neighborhoods and embedded small parks of Phoenix, AZ. Landscape Urban Plan 69:355-368.

McCullagh P, Nelder J (1989) Generalized linear models, $2^{\text {nd }}$ ed. Chapman and Hall/CRC, Boca Raton.

Millward AA, Torchia M, Laursen AE, Rothman LD (2014) Vegetation placement for summer built surface temperature moderation in an urban microclimate. Environ Man 53:1043-1057.

Multi-resolution land characteristics (MRLC) consortium (2011) The national land cover database: percent developed imperviousness. Available from http://www.mrlc.gov

National Oceanic and Atmospheric Administration (NOAA) Office for Coastal Management (2010) Coastal Change Analysis Program (C-CAP) Regional Land Cover Database. Available from http://www.coast.noaa.gov/dataregistry/search/dataset/info/forestfrag

Nowak DJ, Rowntree RA, McPherson EG, Sisinni SM, Kerkmann ER, Stevens JC (1996) Measuring and analyzing urban tree cover. Landscape Urban Plan 36:49-57. 
Pacala S, Roughgarden J (1982) Resource partitioning and interspecific competition in two two-species insular Anolis lizard communities. Science 217:444-446.

Perry G, Buchanan BW, Fisher RN, Salmon M, Wise SE (2008) Effects of artificial night lighting on amphibians and reptiles in urban environments. In Urban Herpetology (Mitchell JC, Jung Brown RE, Bartholomew B, eds). Society for the Study of Amphibians and Reptiles, pp. 239-256.

Petren K, Case TJ (1996) An experimental demonstration of exploitation competition in an ongoing invasion. Ecology 77:118-132.

Pianka ER (1981) Competition and niche theory. In Theoretical Ecology (May RM, ed). Blackwell, pp 167-196.

Pickett STA, Cadenasso ML Grove JM, Nilon CH, Pouyat RV, Zipperer WC, Costanza R (2001) Urban ecological systems: linking terrestrial ecological, physical, and socioeconomic components of metropolitan areas. Annu Rev Ecol Syst 32:127-157.

R Core Team (2013) R: A language and environment for statistical computing. R Foundation for Statistical Computing, Vienna, Austria. Available from http://www.R-project.org/

Ramalho CE, Hobbs RJ (2011) Time for a change: dynamic urban ecology. Trends Ecol Evol 27:179-188.

Rizwan AM, Dennis YCL, Liu C (2008) A review of the generation, determination and mitigation of Urban Heat Island. J Environ Sci 20:120-128.

Royle JA, Nichols JD (2003) Estimating abundance from repeated presence-absence data or point counts. Ecology 84:777-790.

Rummel J, Roughgarden J (1985) Effects of reduced perch-height separation on competition between two Anolis lizards. Ecology 66:430-444.

Salzburg MA (1984) Anolis sagrei and Anolis cristatellus in Southern Florida: a case study in interspecific competition. Ecology 65:14-19.

Santos T, Diaz JA, Perez-Tris J, Carbonell R, Tellera JL (2008) Habitat quality predicts the distribution of a lizard in fragmented woodlands better than habitat fragmentation. Animal Conserv 11:46-56.

Sarre S, Smith GT, Meyers JA (1995) Persistence of two species of gecko (Oedura reticulata and Gehyra variegata) in remnant habitat. Biol Conserv 71:25-33. 
Schwartz A, Thomas R (1975) A checklist of West Indian amphibians and reptiles. Special Publication. Carnegie Museum of Natural History 1:1-216.

Shochat E, Warren PS, Faeth SH, McIntyre NE, Hope D (2006). From patterns to emerging processes in mechanistic urban ecology. Trends Ecol Evol 21:186-191.

Stuart YE, Campbell TS, Hohenlohe PA, Reynolds RG, Revell LJ, Losos JB (2014) Rapid evolution of a native species following invasion by a congener. Science 346 : 463-466.

Sullivan BK, Sullivan KO, Vardukyan D, Suminski T (2014) Persistence of Horned Lizards (Phrynosoma spp.) in urban preserves of Central Arizona. Urban Ecosyst 17:707-717.

White CR (2003) Allometric analysis beyond heterogeneous regression slopes: use of the Johnson-Neyman technique in comparative biology. Physiol Biochem Zool 76:135-140.

Wilson LD, Porras L (1983) The ecological impact of man on the south Florida herpetofauna. University of Kansas Museum of Natural History Special Publication No. 9:1-89.

Wong NH, Yu C (2005) Study of green areas and urban heat island in a tropical city. Habitat International 29:547-558. 
Supplementary Table 1. Estimates of detection probability calculated from singleseason presence-absence occupancy models using sampling covariates of each surveyor and all surveyors combined. Models were built using three repeat surveys of 38 independent sampling points. Mean values are shown with $1 \mathrm{SE}$ in parentheses. No variation exists for PV detection probabilities because this surveyor was present for each sampling event. Low detection probabilities for $A$. equestris likely reflect the low numbers observed for this species (Table 3). Estimates of detection probabilities for the three most common species were sufficiently high $(>0.87)$ to consider detection unlikely to influence subsequent analyses of presence-absence and abundance.

\begin{tabular}{lcccc}
\hline Species & $\begin{array}{c}\text { Model } \\
\text { psi(.),p(JK) }\end{array}$ & psi(.),p(PV) & psi(.),p(RS) & psi(.),p(All Surveyors) \\
\hline A. cristatellus & 0.9003 & 0.6340 & 0.7781 & 0.8807 \\
& $(0.039)$ & $(0.000)$ & $(0.035)$ & $(0.020)$ \\
A. sagrei & 0.7368 & 0.9298 & 0.5921 & 0.9298 \\
& $(0.033)$ & $(0.000)$ & $(0.024)$ & $(0.012)$ \\
A. distichus & 0.7018 & 0.8772 & 0.6097 & 0.8772 \\
& $(0.028)$ & $(0.000)$ & $(0.028)$ & $(0.006)$ \\
A. carolinensis & 0.6524 & 0.7240 & 0.5766 & 0.7302 \\
& $(0.021)$ & $(0.000)$ & $(0.020)$ & $(0.010)$ \\
A. equestris & 0.4021 & 0.2323 & 0.4479 & 0.2056 \\
& $(0.014)$ & $(0.000)$ & $(0.013)$ & $(0.009)$ \\
\hline
\end{tabular}


Supplementary Table 2. Proportion of forest fragmentation using previously defined forest categories and impervious surface cover using two spatial scales for the study area and core area in the Miami.

\begin{tabular}{|c|c|c|c|}
\hline Attribute & Category & $\begin{array}{l}\text { Proportion of } \\
\text { Study Area } \\
\left(1,511 \mathrm{~km}^{2}\right)\end{array}$ & $\begin{array}{l}\text { Proportion of } \\
\text { Core Area } \\
\left(33.63 \mathrm{~km}^{2}\right)\end{array}$ \\
\hline \multirow[t]{5}{*}{ Forest fragmentation } & Core Forest & 0.02 & 0.06 \\
\hline & Patch Forest & 0.03 & 0.06 \\
\hline & Perforated Forest & 0.00 & 0.01 \\
\hline & Edge Forest & 0.03 & 0.13 \\
\hline & Non-forest & 0.92 & 0.73 \\
\hline \multirow{4}{*}{ Impervious surface cover (within $15 \mathrm{~m}$ ) } & $0-20 \%$ & 0.43 & 0.59 \\
\hline & $21-40 \%$ & 0.27 & 0.28 \\
\hline & $41-60 \%$ & 0.18 & 0.08 \\
\hline & $61-100 \%$ & 0.13 & 0.06 \\
\hline \multirow[t]{4}{*}{ Impervious surface cover (within $75 \mathrm{~m}$ ) } & $0-20 \%$ & 0.47 & 0.57 \\
\hline & $21-40 \%$ & 0.20 & 0.26 \\
\hline & $41-60 \%$ & 0.16 & 0.09 \\
\hline & $61-100 \%$ & 0.17 & 0.08 \\
\hline
\end{tabular}


Supplementary Fig. 1. The distribution of A. cristatellus in the Miami metropolitan area showing presence (purple) and absence (white) points for a) the entire area surveyed including regional waste transfer stations and municipal parks and b) a view of the core distribution in South Miami and Key Biscayne (see attached .kmz file).

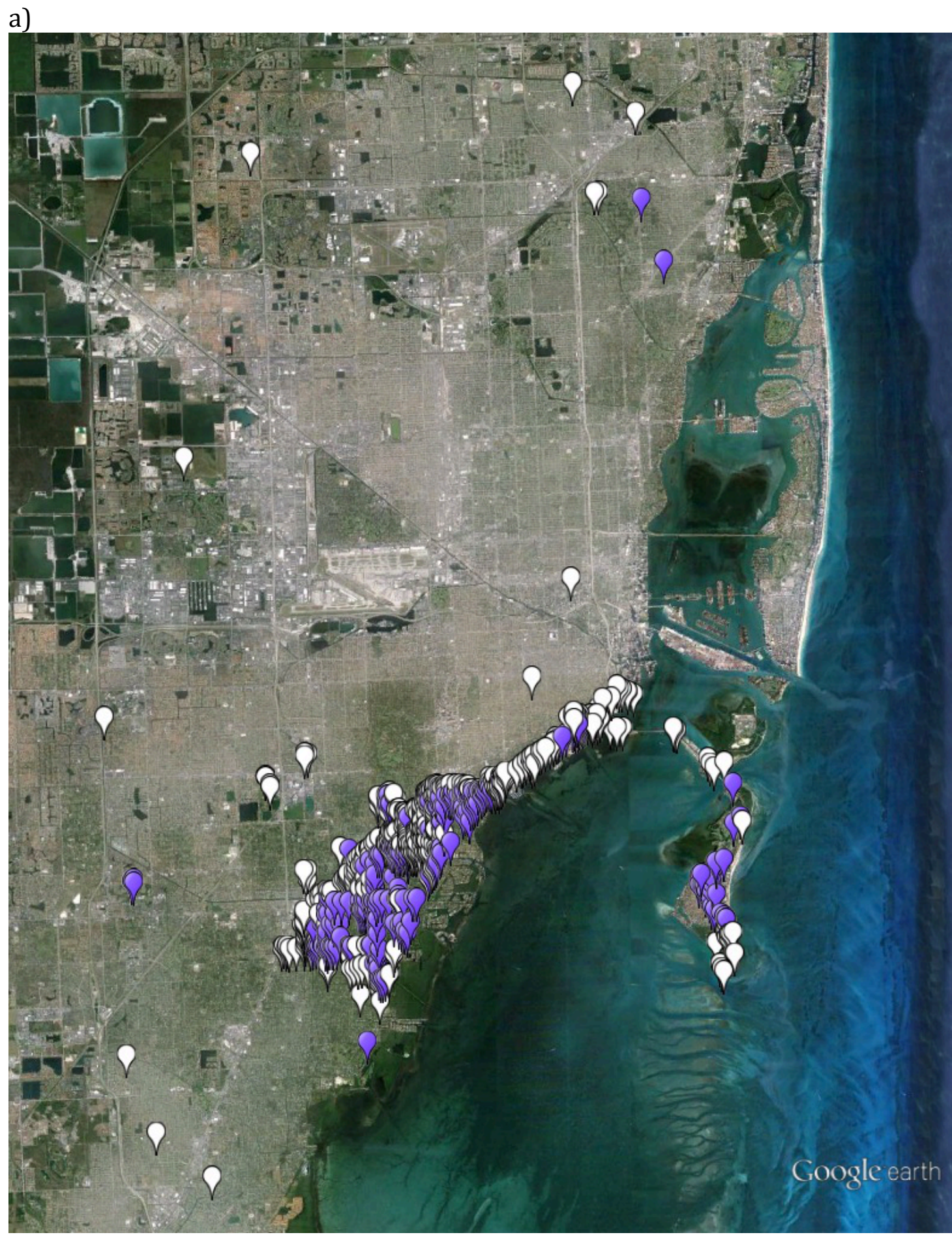


b)

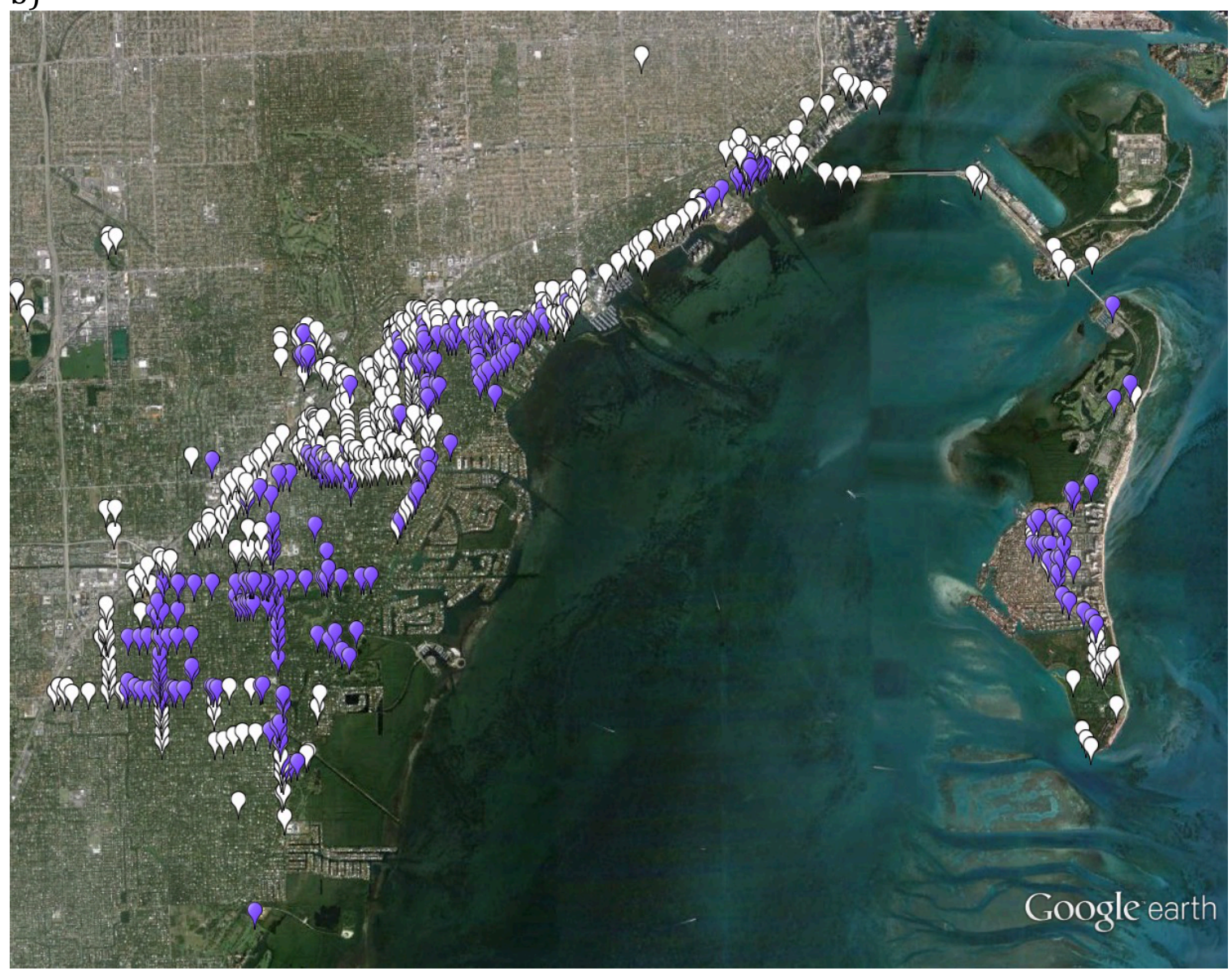


Supplementary Fig. 2. Map showing the location of the five plots and 19 transects in South Miami used to survey for the presence of $A$. cristatellus. We established plots crossing observed transitions from presence (red rectangles) to absence (white rectangles) of $A$. cristatellus based on preliminary surveys. In each plot, we established three to six roadside transects (blue lines) running perpendicular to the transition zone.

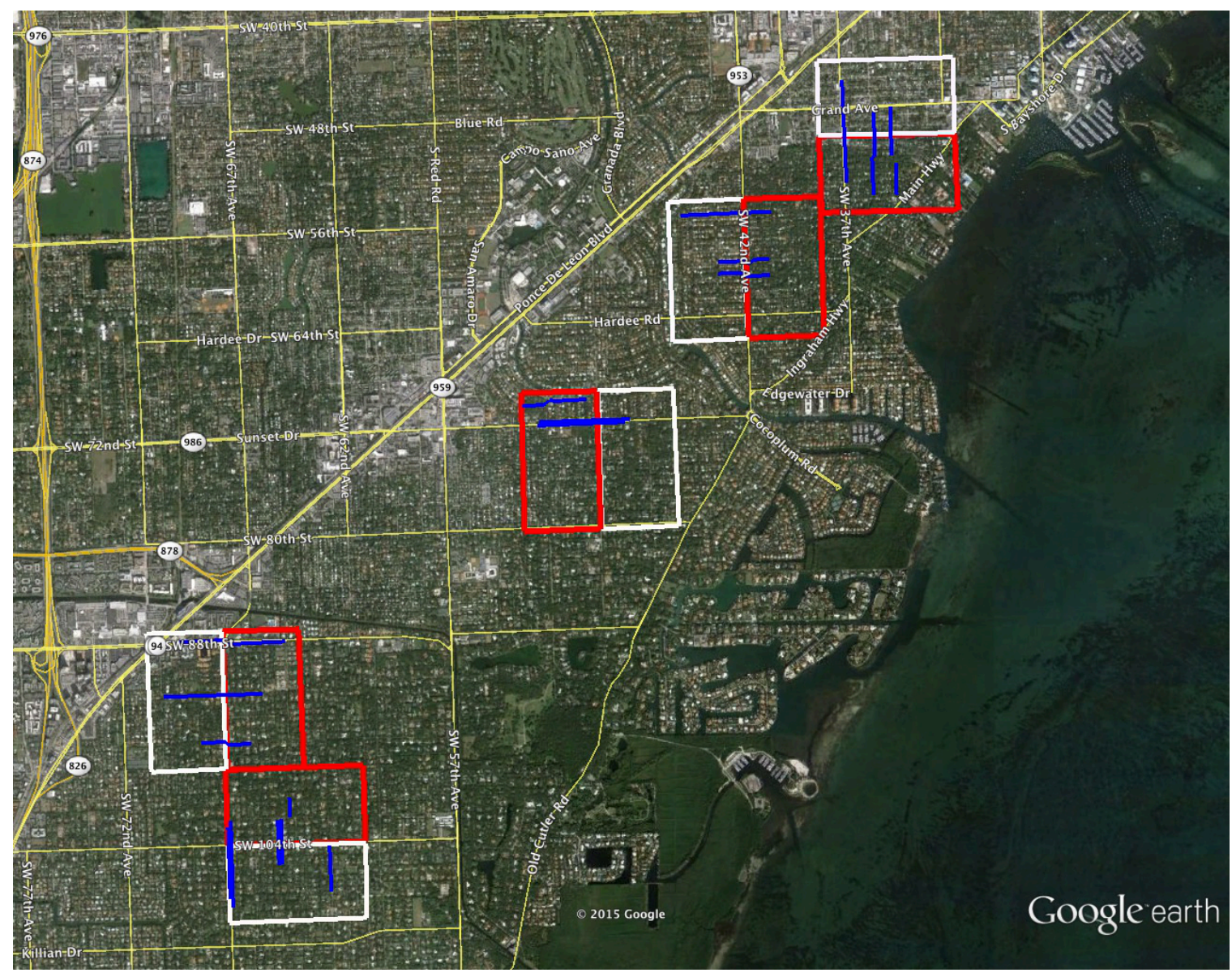


Supplementary Figure 3. GIS-based map for a portion of the distribution of $A$. cristatellus in Coconut Grove showing presence and absence points and a) percentage of impervious surface divided into four categories and $b$ ) the four forest fragmentation types. This is a color version of Fig. 2 .

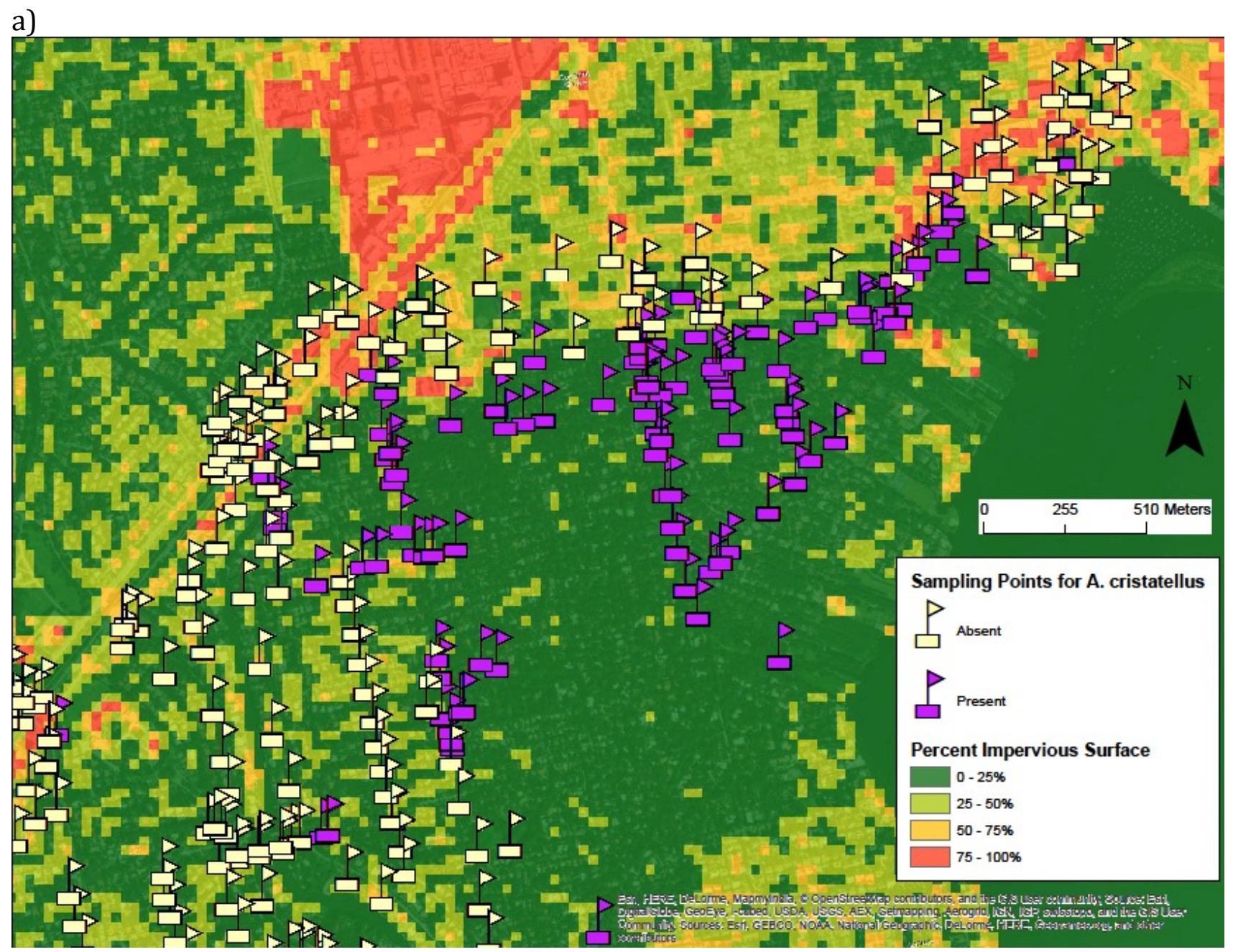


b)

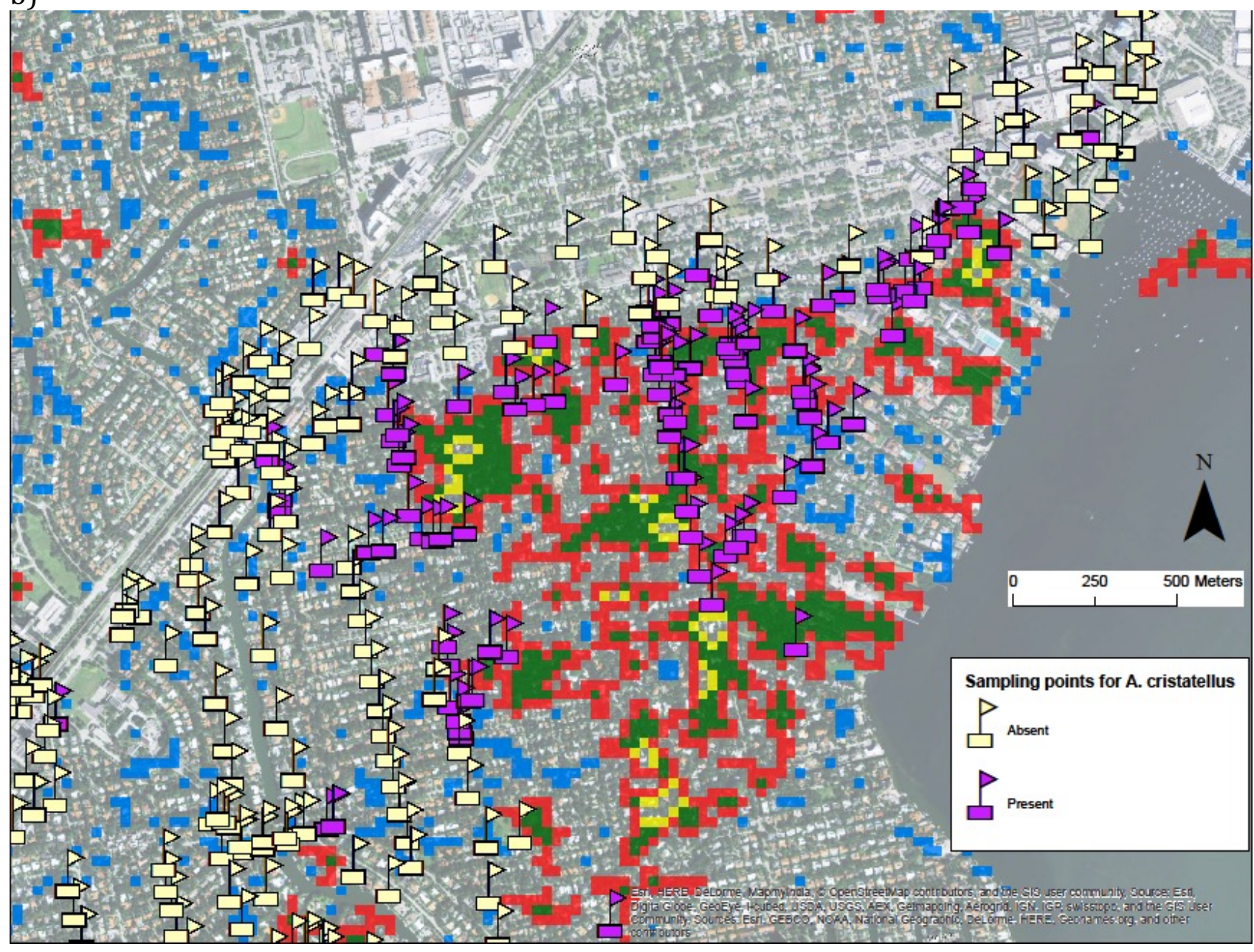


Supplementary Figure 4. Overstory canopy photos facing in the four cardinal directions for representative a) shaded and b) open canopy trees. Percentage of overstory cover is shown next to each photo.

a)

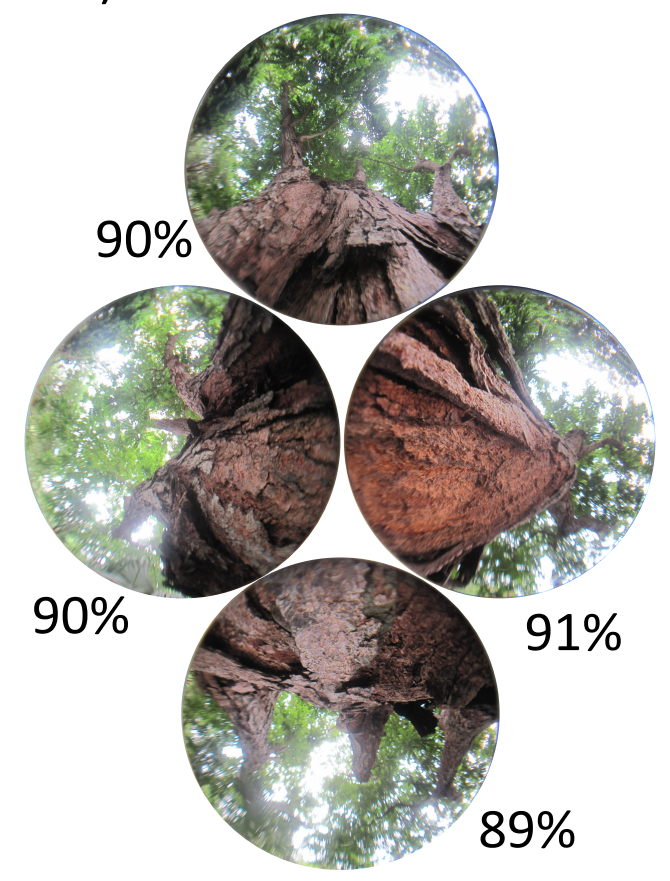

b)

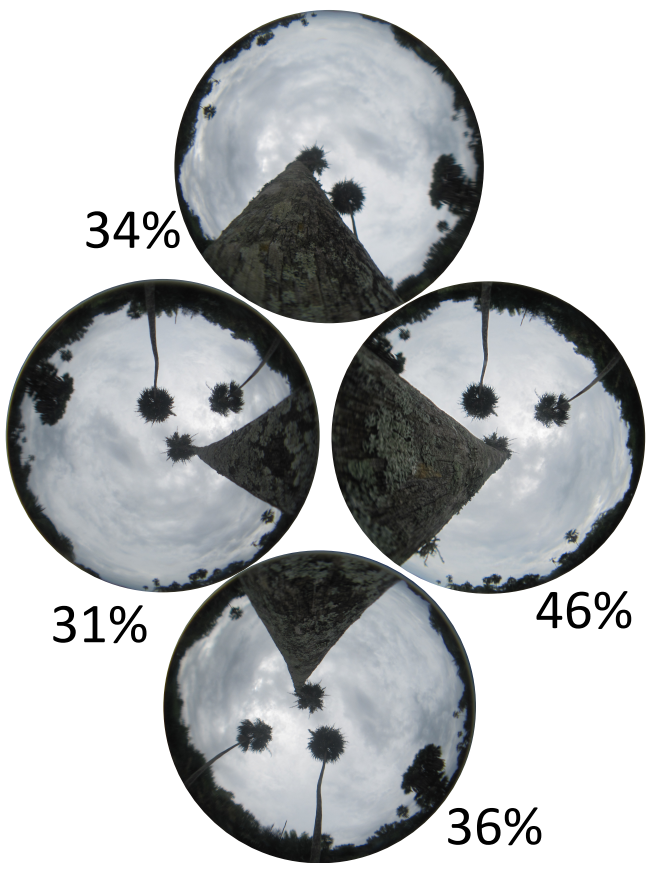

